\title{
Identification of plant promoter constituents by analysis of local distribution of short sequences
}

Yoshiharu Y Yamamoto*1,2, Hiroyuki Ichida1,3, Minami Matsui ${ }^{4}$, Junichi Obokata르. Tetsuya Sakurai ${ }^{5}$, Masakazu Satou ${ }^{3}$, Motoaki Seki' ${ }^{3}$, Kazuo Shinozaki ${ }^{5}$ and Tomoko Abe ${ }^{1}$

Address: ${ }^{1}$ Application and Development Group, RIKEN FRS, Hirosawa 2-1, Wako, Saitama 351-0198, Japan, ${ }^{2}$ Center for Gene Research, Nagoya University, Furo-cho, Chikusa-ku, Nagoya, Aichi 464-8602, Japan, ${ }^{3}$ Graduate School of Science and Technology, Chiba University, Matsudo 648 , Matsudo, Chiba 271-8510, Japan, ${ }^{4}$ RIKEN Genomic Sciences Center, Suehirocho 1-7-22, Tsurumiku, Yokohama, Kanagawa 230-0045, Japan and ${ }^{5}$ RIKEN Plant Science Center, Suehirocho 1-7-22, Tsurumiku, Yokohama, Kanagawa 230-0045, Japan

Email: Yoshiharu Y Yamamoto* - yyoshi@gene.nagoya-u.ac.jp; Hiroyuki Ichida - ichida@riken.jp; Minami Matsui - minami@riken.jp; Junichi Obokata - obokata@gene.nagoya-u.ac.jp; Tetsuya Sakurai - stetsuya@psc.riken.jp; Masakazu Satou - msatou@gsc.riken.go.jp; Motoaki Seki - mseki@rtc.riken.go.jp; Kazuo Shinozaki - sinozaki@rtc.riken.go.jp; Tomoko Abe - tomoabe@riken.jp

* Corresponding author

Published: 8 March 2007

BMC Genomics 2007, 8:67 doi:10.1/86/147|-2164-8-67
Received: 21 November 2006

Accepted: 8 March 2007

This article is available from: http://www.biomedcentral.com/I47I-2/64/8/67

(c) 2007 Yamamoto et al; licensee BioMed Central Ltd.

This is an Open Access article distributed under the terms of the Creative Commons Attribution License (http://creativecommons.org/licenses/by/2.0), which permits unrestricted use, distribution, and reproduction in any medium, provided the original work is properly cited.

\begin{abstract}
Background: Plant promoter architecture is important for understanding regulation and evolution of the promoters, but our current knowledge about plant promoter structure, especially with respect to the core promoter, is insufficient. Several promoter elements including TATA box, and several types of transcriptional regulatory elements have been found to show local distribution within promoters, and this feature has been successfully utilized for extraction of promoter constituents from human genome.

Results: LDSS (Local Distribution of Short Sequences) profiles of short sequences along the plant promoter have been analyzed in silico, and hundreds of hexamer and octamer sequences have been identified as having localized distributions within promoters of Arabidopsis thaliana and rice. Based on their localization patterns, the identified sequences could be classified into three groups, pyrimidine patch (Y Patch), TATA box, and REG (Regulatory Element Group). Sequences of the TATA box group are consistent with the ones reported in previous studies. The REG group includes more than 200 sequences, and half of them correspond to known cis-elements. The other REG subgroups, together with about a hundred uncategorized sequences, are suggested to be novel cis-regulatory elements. Comparison of LDSS-positive sequences between Arabidopsis and rice has revealed moderate conservation of elements and common promoter architecture. In addition, a dimer motif named the YR Rule ( $\mathrm{C} / \mathrm{T} \mathrm{A} / \mathrm{G})$ has been identified at the transcription start site $(-I /+I)$. This rule also fits both Arabidopsis and rice promoters.
\end{abstract}

Conclusion: LDSS was successfully applied to plant genomes and hundreds of putative promoter elements have been extracted as LDSS-positive octamers. Identified promoter architecture of monocot and dicot are well conserved, but there are moderate variations in the utilized sequences. 


\section{Background}

The determination of complete genome sequences has allowed analysis by various statistical methods that have furthered understanding of the function of genomes. Analysis of promoter structure is one of the most important issues. Understanding of promoter structure allows predictions concerning promoter positions and expression profiles, and sheds light on hidden transcriptional networks.

Several functional elements have been identified as promoter constituents for precise and regulated transcriptional initiation: TATA box, Initiator (Inr) motif, Downstream Promoter Element (DPE, found from drosophila), TFIIB-Recognition Element (BRE), and so-called cis-regulatory elements [1-3]. In addition, some mammalian promoters are associated with CpG islands [4,5], which is related to the Sp1 recognition site [6] and have some relationship with gene regulation by DNA-methylation $[3,7]$. Human transcriptional regulatory elements are reported to make clusters (modules) at the promoter region as well as the $3^{\prime}$ end of a gene [8]. Transcription start sites (TSS) in plant promoters have a CG-compositional strand bias, or GC-skew, where $\mathrm{C}$ is more frequently observed in the (+) strand than G $[9,10]$. Some of these features are well understood and some are not, but all these features are useful to understand individual promoters. Some of the above features have been utilized for promoter prediction [11-13]. Although these studies obtain certain success, our current knowledge of promoters is still insufficient [13].

Availability of microarray data on co-regulated gene expression on a genomic scale has enabled the prediction of novel cis-elements involved in gene regulation. Several approaches have been developed for this detection of consensus sequences in a co-regulated promoter set (Gibbs Motif Sampling [14,15], MEME [16]), and detection of over-represented sequence in co-regulated promoters with a set of reference sequences $[17,18]$. These approaches are also applicable to chromatin immunoprecipitation (ChIP) data $[19,20]$. In addition, identification of conserved promoter sequences by comparative genomics supports the prediction of regulatory elements [21-24].

Studies on plant transcription factors and functional cisregulatory elements have been summarized in several databases, and the collective information of cis-elements and/or transfactor-binding DNA sequences are utilized for interpretation of plant promoters (PLACE: [25], AGRIS: [26], AthaMap: [27,28]). Basis of these databases are published articles reporting analyses of individual promoters or transfactors, rather than large scale genomic analyses. Therefore, lack of large scale functional analyses of transcription factors in plant science is reflected in these databases as well.

In contrast to the above fact-based approaches, in silico prediction of plant promoter elements by survey of the Arabidopsis genome is also reported. Molina and Grotewold applied the MEME and Gibbs sampling methods to Arabidopsis core promoter regions with genomic scale, and detected several motifs including a plant TATA motif and microsatellites [29].

Recent studies on mammalian promoter elements have revealed that some of them have localized appearance along the promoter region, exemplified by the TATA box [30], and binding sites for NRF-1, Sp1, CREB, ATF, and E2F [31]. These studies evoke the idea that localized distribution is a signature of a functional element of the promoter. Recently, this feature was successfully utilized for extraction of functional sequences from human promoters [32]. Large-scale deletion analysis of human promoters suggested that there is some relationship between presence of functional elements and distance from TSS [33].

In this report, we have detected hundreds of short sequences showing localized distribution in plant promoters by comprehensive analyses of short sequences. The extracted sequences are mentioned as "LDSS (Local Distribution of Short Sequence)-positive" in this work. These sequences includes TATA boxes, various regulatory sequences identified in previous studies, a novel sequence group that would be a general component of a core promoter, and also many novel sequences that share many characteristics with regulatory sequences. Our analyses have also revealed conservation of the promoter architecture between monocot and dicot plants.

\section{Results}

\section{Patterns of distribution of peaks}

Typically, DNA elements recognized by a protein (complex) is within the range of 5 to 15 bp long [34]. Within this range, we decided to analyze localization patterns of hexamer and octamer sequences. Our results suggest that sequences longer than 9 bps would not provide enough number of appearance to survive statistical analysis.

For each hexamer sequence, a distribution profile in relation to distance from the TSS was analyzed for Arabidopsis thaliana. Looking through all the distribution profiles, we noticed that there are quite a few patterns. Most sequences have a flat distribution profile with no special tendency (Fig. 1, GAAGAG). Sometimes the base line has a slight slope with a higher frequency toward the TSS. There are also groups with peaks, and they can be classified accord- 
ing to the peak position. We refer these sequences as LDSS-positive.

One example of a LDSS-positive sequence, (Fig. 1, CTCTTC) has a peak of appearance at the TSS. Its complementary sequence (Fig. 1, GAAGAG) has a distinct distribution profile, showing that its appearance is sensitive to the direction of transcription. Although hexamers with this type of distribution profile tend to have only $\mathrm{C}$ and $\mathrm{T}$ in the sequence (see later), there seems to be weak sequence preference, and not all the sequences filled with $\mathrm{C}$ and $\mathrm{T}$ show a peak-positive distribution (Fig. 1, CCTTTT is a peak-negative example).

A second example (Fig. 1, CTATAA) is a TATA box-related sequence. This has a peak around $-35 \mathrm{bp}$, and the peak is very sharp. The complementary sequence showed a different pattern with no peak (Fig. 1, TTATAG).

A third example (Fig. 1, TGGGCC) has a relatively wide and low peak. Complementary sequence of this sequence shows the same peak (Fig. 1, GGCCCA). Peak position and direction-insensitivity suggest that sequences with this type of distribution profile are so-called cis-regulatory sequences involved in transcriptional regulation [34]. In fact, TGGGCC in Figure 1 is reported to be necessary for meristematic expression in Arabidopsis, and mutation to TGAACC abolished the expression (Element II of Arabidopsis PCNA-2, [35]). Interestingly, distribution of the mutated sequence does not have any peaks (Fig. 1, TGAACC), demonstrating a good correlation between functionality and peak distribution. In addition, one base substitution, TGAGGCC, also caused the loss of the peak (Fig. 1). It is common that one base substitution drastically changes the distribution profile (data not shown).

As controls, a set of random genomic sequences of $1 \mathrm{~kb}$ length was used for the distribution analysis instead of the promoter database. When sequences with distribution patterns of peak-positive sequences were applied to this analysis, they were found to have no peaks in the random genome fragments (Fig. 1, CTCTTC/random genome, CTATAA/random genome, TGGGCC/random genome).

Beside LDSS-positive elements, there are many LDSS-negative sequences. Among them, frequently observed sequences beyond the theoretical occurrence rate $(0.24$ per a $1 \mathrm{~kb}$ region) are rich in AT and might promote promoter context, and rare sequences are rich in GC and they might disturb promoter function when located within the promoter region. Therefore, it might be possible to utilize these LDSS-negative sequences as well for evaluation of promoter context.

\section{Parameters for peak evaluation}

Figure 2A shows a close-up of a typical distribution profile of the regulator type. In order to detect peak-positive sequence, we calculated several parameters. Curve fitting with Gaussian did not give good results (data not shown), because the peak shape is not symmetrical, as seen in the figure. Through analysis of distribution profiles of all the hexamers, we noticed that all of the observed peaks were located downstream of -200 bp. This enabled a base line to be established (Base in the figure) as an average of occurrence between $-1,000$ and $-500 \mathrm{bp}$. Then we calculated the Relative Peak Height (RPH), and Relative Peak Area (RPA) for evaluation of peak strength. Fluctuation around the base line between $-1,000$ and -500 bp was also evaluated (see figure legend).

Figure 2B shows the relationship between peak position and a parameter of peak strength. As shown, all the strong peaks locate downstream of -200 bp while weak peaks are scattered throughout the promoters. One important point of the figure is the continuous distribution of hexamers across the vertical axis. The continuous nature was also observed when RPH or RPA was represented in the graph on the vertical axis (data not shown). These results mean that there is no clear way to separate peaky and flat groups. In this study, we took a strategy to list sequences with strong peaks, leaving out a flat group and a group with ambiguous peaks.

Considering peak height, peak area, and fluctuation from the base line, we selected 247 sequences from all the hexamers as peak positive (Fig. 2B, black dots, Table S1 [see Additional file 1]).

\section{Peak-positive hexamers can be classified according to their peak position}

The LDSS-positive hexamers identified were then classified into three major groups as mentioned above. The first group, including CTCTTC, in Figure 1, localize from -100 to -13 bp. They typically have a peak at the most downstream region of the promoter (position -13, Table 1), but peak positions distribute from -13 to -60 . Most of their sequences are composed of only $\mathrm{C}$ and $\mathrm{T}$, we refer to this group as $\mathrm{Y}$ Patch ( $\mathrm{Y}$ for pyrimidine). As shown in the table, Y Patch sequences are found in the majority of Arabidopsis promoters.

The second group contains TATA box-related sequences. An example is shown as CTATAA in Figure 1. The characteristics of this group are high peak height, narrow peak width, and stringent peak position (Table 1, TATA Box). Similar to Y Patch, the TATA box group sequences are also found in the majority of Arabidopsis promoters, although promoters with the TATA Box within the peak are is about 1,000 or less for each sequence. 

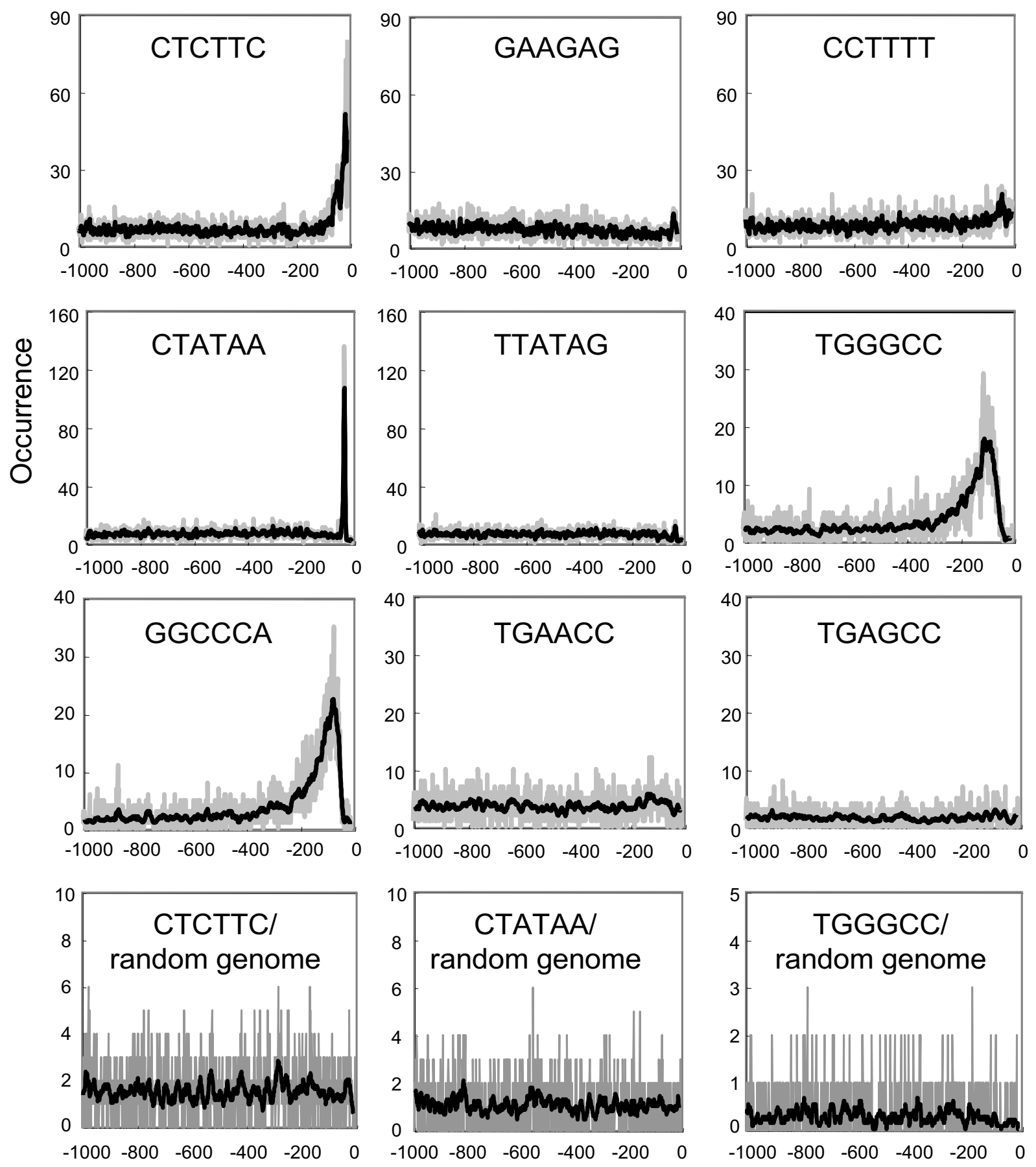

\section{Position from TSS}

\section{Figure I}

Examples of distribution of peaks. Several examples of hexamer analysis against Arabidopsis promoters are shown. The vertical axis indicates the total count of the whole promoter database. Gray and solid lines show raw and average with 15 bin (width of window), respectively. Instead of the promoter database, a set of 3,000 random fragments of I kb length from the Arabidopsis genome were used for the occurrence analysis as negative controls (shown as "random genome" in the bottom columns). 


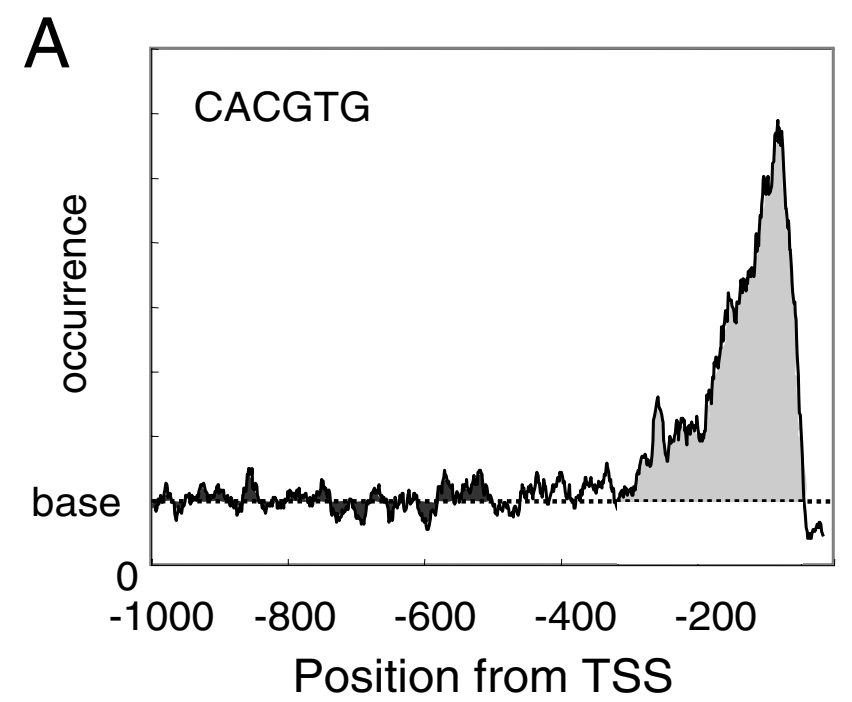

B

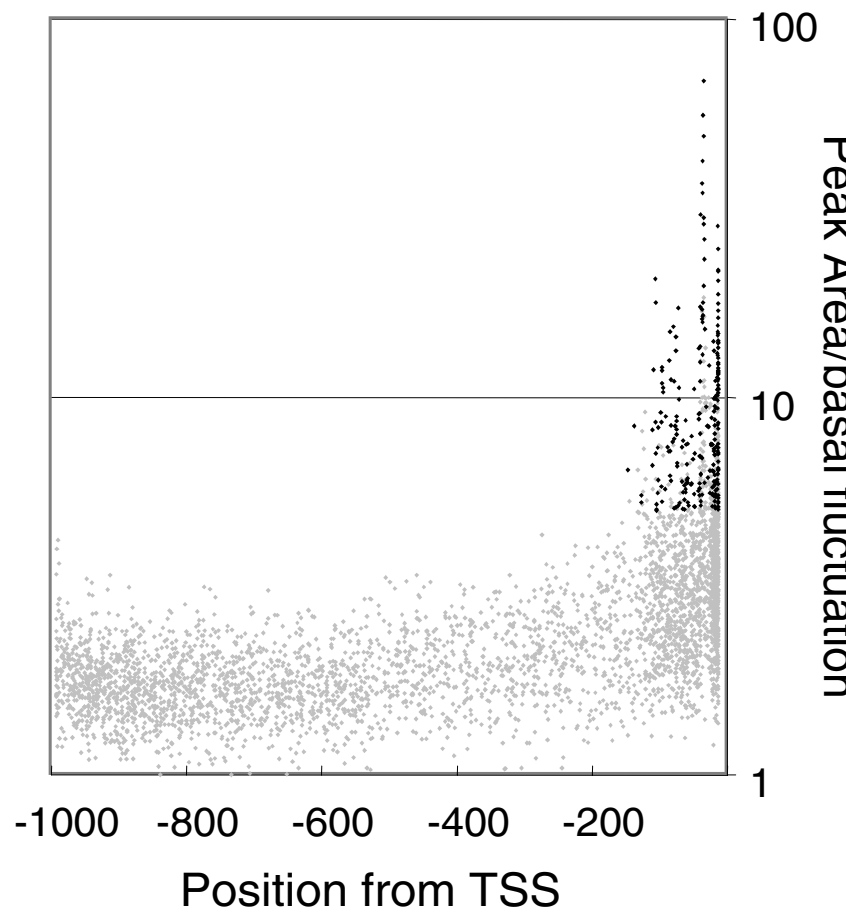

Figure 2

Parameters for peak detection. (A) Graph is a distribution profile of CACGTG in Arabidopsis promoters. Average with I5 bin is shown. The dotted line indicates the Base Line, which is an average of $-I, 000$ to -500 . The light grey area shows Peak Area. The dark grey area is $\Delta$ area, an indication of the fluctuation from the Base Line from $-I, 000$ to -500 . In addition, the following parameters have been defined: Relative Peak Area $($ RPA $)=$ Peak Area/total area; Relative Peak Height $($ RPH $)=p e a k$ height/Base Line; Peak Area/basal fluctuation = Peak Area/ $\Delta$ area per peak width; Peak height/SD = peak height/standard deviation of occurrence from - 1000 to -500 . Several parameters of this graph are shown in Table 2 (CACGTG). (B) All the hexamers were analyzed to obtain various parameters, and (Peak Area/basal fluctuation) and peak position were calculated. The graph shows the results. Each dot shows the data of an individual hexamer. Among the 4,096 hexamers (grey dots), 247 peak positive hexamers have been selected (solid dots). The graph demonstrates that hexamers with a significant value have a peak position from -200 to -13 (the most downstream position after smoothing). 
Table I: Y Patch and TATA Box identified from Arabidopsis hexamer analysis

\begin{tabular}{|c|c|c|c|c|c|}
\hline Sequence & Peak position' (bp) & Peak width $^{2}$ (bp) & \#promoter ${ }^{3}$ & Relative Peak Height (RPH) & Relative Peak Area (RPA) \\
\hline \multicolumn{6}{|l|}{ Y Patch } \\
\hline ТСТСТС & -13 & 158 & 6,741 & 10.96 & 0.25 \\
\hline ССТСТС & -13 & 107 & 3,106 & 8.13 & 0.20 \\
\hline СТTСТС & -13 & 88 & 5,916 & 7.64 & 0.15 \\
\hline СТССТС & -13 & 81 & 3,180 & 7.23 & 0.12 \\
\hline СТСТТС & -13 & 91 & 5,393 & 7.02 & 0.14 \\
\hline СТСТСС & -13 & 108 & 3,153 & 6.95 & 0.16 \\
\hline ТСССТС & -13 & 93 & 2,140 & 6.13 & 0.15 \\
\hline TТСТTC & -13 & 75 & 8,829 & 5.78 & 0.11 \\
\hline ТТСТСТ & -13 & 109 & 8,314 & 5.77 & 0.12 \\
\hline \multicolumn{6}{|l|}{ TATA Box } \\
\hline TATAAA & -35 & 30 & 10,704 & 9.0 & 0.10 \\
\hline TATATA & -36 & 27 & 10,315 & 6.38 & 0.07 \\
\hline ATATAA & -35 & 27 & 10,062 & 6.14 & 0.07 \\
\hline ATAAAT & -35 & 27 & 10,572 & 5.14 & 0.05 \\
\hline TAAATA & -34 & 25 & 9,801 & 4.65 & 0.04 \\
\hline ATATAT & -35 & 24 & 10,412 & 3.84 & 0.04 \\
\hline TTATAA & -36 & 23 & 9,172 & 3.36 & 0.03 \\
\hline TTATAT & -36 & 23 & 9,639 & 3.10 & 0.03 \\
\hline
\end{tabular}

In this analysis, -13 is the position for an average from -20 to -6 that covers a region from -20 to $-I$, so -13 is the most downstream position. 2Peak width at the bottom of the peak.

${ }^{3}$ Number of promoters containing the element out of 15,607 Arabidopsis promoters (-I,000 to $\left.-\mathrm{I}\right)$. Number of promoters containing an element within the peak area can be roughly estimated by \#promoters $\times$ RPA. For example, TATAAA is found in approx. I,070 promoters within the peak area $(10,704 \times 0.10)$.

The third group, including TGGGCC in Figure 1, is referred to as REG, for Regulatory Element Group, in this study. The peak positions of this group locate around -80 bp, and they have a wide peak width in comparison with that of the TATA box group (Table 2). Another feature of the group is high coverage of Peak Area against total area. This means high specificity of localization within a promoter. As shown in Relative Peak Area (RPA) of the table, around $50 \%$ to $30 \%$ of a REG sequence is found in the peak area. These ratios are much higher than those of the Y Patch (25 to $10 \%$ ) or TATA box (11 to $5 \%$ ) groups. Compared to these, the number of promoters containing a REG sequence is smaller, consistent with the idea that each REG is not a component of the general core promoter but a specific regulator of gene expression. In fact, Table 2 contains several known cis-regulatory elements, including Element II of Arabidopsis PCNA-2 (GGCCCA, TGGGCC, and AGCCCA) [35] and G-box/ABRE (CACGTG, CGTGGC, CCACGT, and GCCACG) [36].

In addition to these three groups, there is also small number of exceptional hexamers with peak positions in the core promoter (-13 to -60$)$. They might constitute a minor type(s) within the core promoter (Table S1, "others" [see Additional file 1]. See also Table S2 and S3 for these elements). The complete list of the extracted sequences is shown in Table S1. The table shows $103 \mathrm{Y}$ Patch, 39 TATA-related, 38 REG, and 22 unclassified hexamer sequences.

\section{Directional preference relative to transcription}

Subsequently, we examined if the orientation of the hexamers is critical. The identified hexamers were tested to determine if their complementary sequences were also included or not. If the complementary sequence was also found in this positive group, the original sequence is considered as direction-insensitive, and if not, direction-sensitive. As shown in Figure 3, the downstream region from -50 , that is known to be the core promoter region [1] and includes the Y Patch and TATA box groups, is occupied with direction-sensitive sequences ("uniq" in the figure), while the upstream region, containing the REG group, is rich in direction-insensitive sequences ("comp" in the figure). These findings are consistent with the established idea that the core promoter determines position and direction of transcription, and cis-elements are direction insensitive. These findings further support the idea that the Y Patch and TATA box sequences are core promoter elements and REG sequences are the cis-elements [34].

\section{Comparison of Arabidopsis and rice promoters}

Subsequently, we analyzed the distribution of octamer sequences. The average of octamer appearance rates is 15.7-fold less than the one of hexamers, consistent with a mathematical expectation of 16-fold difference (data not shown). Because rare sequences tend to show more fluctuations by chance, statistical evaluation was more critical for octamer analysis. We prepared random distribution populations and used them for statistical evaluation of 
Table 2: REGs identified from Arabidopsis hexamer analysis

\begin{tabular}{|c|c|c|c|c|c|}
\hline Sequence & Peak position (bp) & Peak width (bp) & \#promoter & $\begin{array}{c}\text { Relative Peak Height } \\
\text { (RPH) }\end{array}$ & $\begin{array}{c}\text { Relative Peak Area } \\
\text { (RPA) }\end{array}$ \\
\hline AGGCCC & -76 & 326 & 2,005 & 14.78 & 0.54 \\
\hline GGCCCA & -73 & 347 & 1,225 & 12.26 & 0.53 \\
\hline GGGCCT & -106 & 240 & 1,764 & 10.31 & 0.47 \\
\hline TGGGCC & -107 & 262 & 2,867 & 9.29 & 0.46 \\
\hline GGGCCC & -91 & 256 & 711 & 9.51 & 0.44 \\
\hline GCCCAT & -76 & 320 & 2,925 & 8.41 & 0.43 \\
\hline GCCCAA & -72 & 366 & 3,068 & 7.78 & 0.42 \\
\hline AGCCCA & -85 & 284 & 2,963 & 7.53 & 0.39 \\
\hline CACGTG & -80 & 273 & 3,039 & 6.85 & 0.38 \\
\hline AAGCCC & -86 & 299 & 2,593 & 7.48 & 0.37 \\
\hline CGGCCC & -62 & 189 & 732 & 7.66 & 0.36 \\
\hline CCACGT & -83 & 260 & 2,367 & 5.66 & 0.35 \\
\hline ATGGGC & -97 & 295 & 2,836 & 6.29 & 0.35 \\
\hline CGTGGC & -97 & 251 & 1,459 & 5.96 & 0.35 \\
\hline TAGGCC & -75 & 311 & 1,435 & 6.18 & 0.34 \\
\hline CGTGTC & -79 & 289 & 1,909 & 5.57 & 0.33 \\
\hline AAGGCC & -77 & 287 & 1,935 & 6.27 & 0.33 \\
\hline GCGCGT & -59 & 244 & 632 & 5.56 & 0.32 \\
\hline GCCACG & -83 & 215 & $|, 4| \mid$ & 6.64 & 0.31 \\
\hline ACGCGC & -65 & 190 & 655 & 5.08 & 0.31 \\
\hline GGGCCG & -85 & 196 & 711 & 6.01 & 0.30 \\
\hline CACGCG & -138 & 182 & 884 & 5.22 & 0.30 \\
\hline
\end{tabular}

each octamer (Figure S1 [see Additional file 2]). In this study, we have set a p value of $1 \times 10^{-5}$ as a threshold. In addition, data of the complementary sequences was merged only for REG detection to increase total count of an octamer in the database. Through the octamer analyses, we have identified 350 and 418 LDSS-positive core elements (Table S2 [see Additional file 3] and S3 [see Additional file 4]), and 308 and 242 REG sequences from Arabidopsis and rice, respectively (Table S4 [see Additional file 5] and S5 [see Additional file 6]). Sum of the p values for all the extracted octamers of individual species were around $1 \times 10^{-3}$ each, so false-positive sequences by pure random distribution are not likely to be included in the lists.

For comparison of Arabidopsis and rice elements, Relative Peak Height (RPH) values of all the positive octamers in either of the two promoter databases were represented (Fig. 4A). If a sequence has the same RPH value in the Arabidopsis and rice databases, a dot appears on the diagonal line. As shown in the figure, we found that RPH values are moderately conserved between Arabidopsis and rice (Fig. $4 \mathrm{~B})$. The figure also indicates that a considerable number of the sequences have a large difference in the parameter between Arabidopsis and rice. Figure 4B shows Venn diagram of the number of positive octamers in Arabidopsis and rice. As shown in the figure, approximately 30 to $50 \%$ of the octamers are conserved between Arabidopsis and rice for both core groups of Y Patch and TATA box, and the REG group. Presence of all the three categories in Arabidopsis and rice, and sequential conservation as shown in the figure indicate that promoter architecture of these plant species is essentially conserved. On the other hand, divergence of the positive sequences might reflect differentiation of the corresponding trans-factors between these species.

\section{Classification of Arabidopsis LDSS-positive octamers by distribution profiles}

All the LDSS-positive sequences from Arabidopsis were subjected to clustering analysis according to their distribution profiles. As expected from previous hexamer analyses, major clusters are REGs, TATA box, and Y Patch (Fig. 5). As shown in the figure, distribution profiles within each group (clusters) are quite similar, suggesting functional conservation within each group. The observed clear classification of the LDSS-positive sequences, represented in Figure 5, suggest that the local distribution is a quite useful feature in extraction of putative functional elements in the promoter.

\section{Clustering of Arabidopsis REGs based on presence and absence in promoters}

Subsequently, we did classification of 308 Arabidopsis REGs with the aid of the promoter database. For each promoter, number of appearance for each REG was scored, 


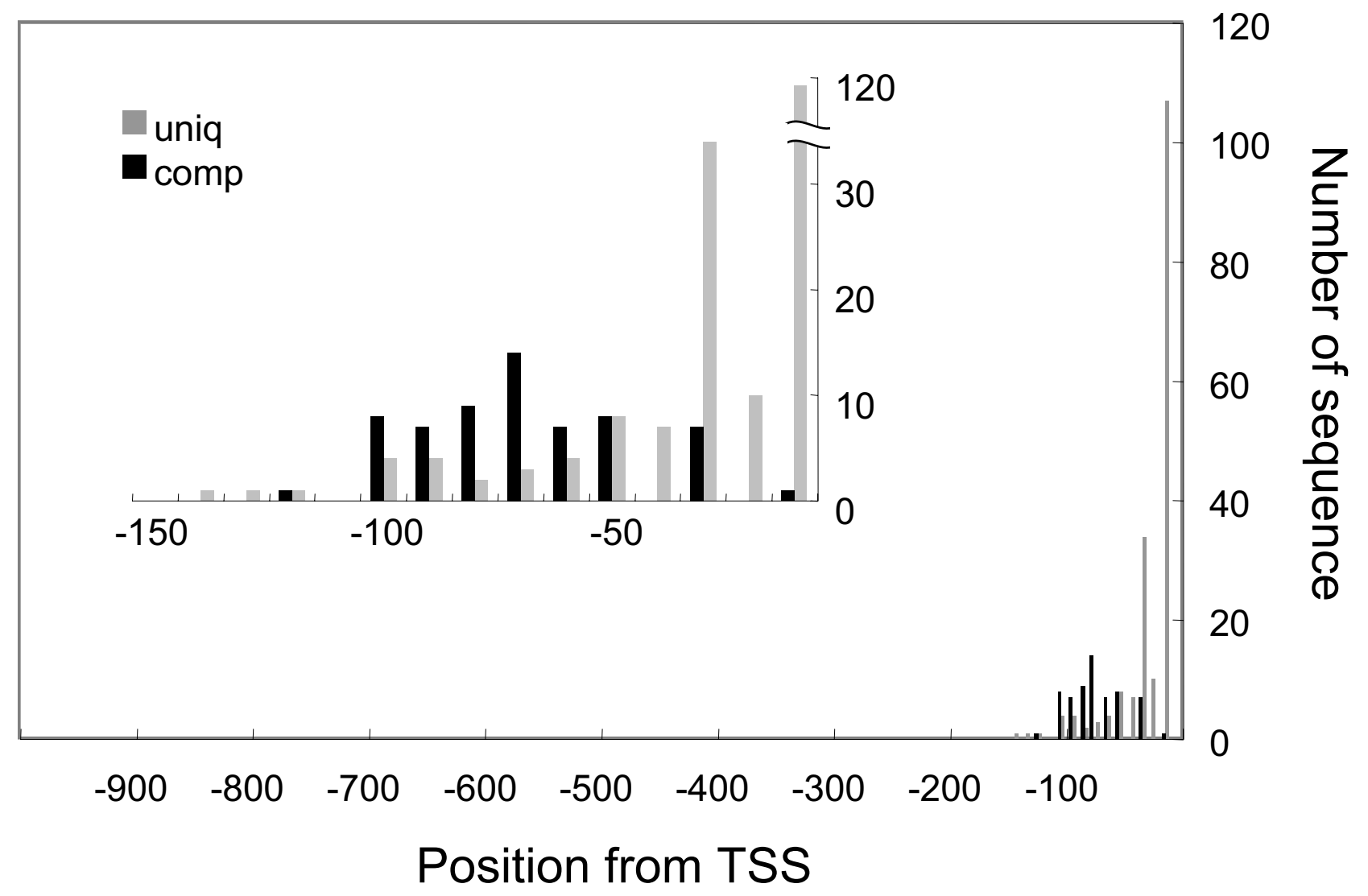

Figure 3

Directional preference of LDSS-positive hexamers. When the corresponding complementary sequence was not found in the LDSS-positive group, the hexamer was counted as "uniq", which means orientation-sensitive. When found, the sequence was counted as "comp", meaning direction-insensitive. The number of both hexamers were counted according to the peak position from the TSS, and summarized in a bar graph. The inset graph is an enlargement to show more detail around the TSS.

and two-dimensional REG-promoter clustering was performed. This REG-promoter association has revealed that 10,334 out of 12,951 Arabidopsis promoters have at least one REG at the region of -400 to $-40 \mathrm{bp}$. This high coverage $(80 \%)$ is due to the long list of REG sequences.

This 2D clustering puts co-localized REGs proximal, and promoters with similar REG compositions also come close. Two promoter clusters are shown in Figure 6A and $6 \mathrm{~B}$. One cluster of promoters (A) are rich in GCCCA-containing REGs, and another cluster (B) have ACGT-containing REGs. GCCCA-containing REGs is the same kind as TGGGCC (Figure 1) and known to show cell cycledependent expression and meristematic expression (Group 1, Table 3). Interestingly, this promoter group is rich in ribosomal proteins. As shown in Figure 6A, as high as $38 \%$ ( 6 out of 16 ) of the annotated promoters are for ribosomal proteins (Fig. 6A, blue). In contrast, ribosomal promoters are not included in the ACGT-containing promoter clusters (Fig. 6B). Instead, the latter cluster is rich in photosynthesis-related genes and stress-responsive genes, both of which would show environmental responses. In fact, as many as 34 out of 38 genes in this cluster with expression data are responsive to light (Fig. 6B, green) or abiotic stress including salt, drought, and cold (Fig. 6B, red and orange), according to public microarray data $[37,38]$. Although this clustering is not so accurate as to distinguish between light and stress responses, it has been proved to classify genes with respect to gene expression with a certain range of accuracy. The results are reasonable 

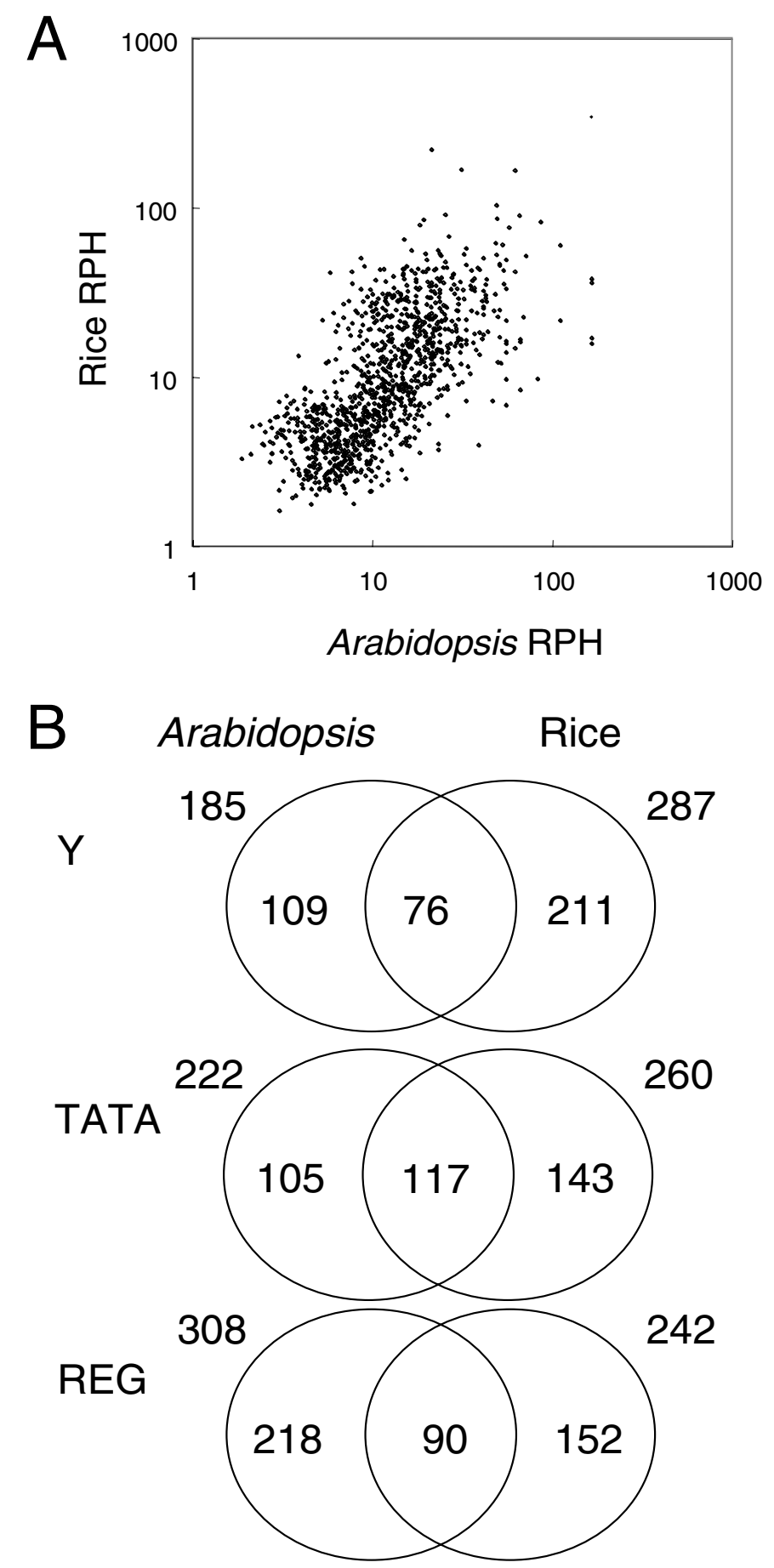

\section{Figure 4}

Comparison of Arabidopsis and rice octamers. (A) 987 octamers that are LDSS-positive in either Arabidopsis or rice promoters were selected and their Relative Peak Height (RPH) was compared and expressed as a scatter plot. Each dot is data from an individual octamer sequence. (B) LDSS-positive octamer sequences of Arabidopsis and rice were compared, and common sequences found in both sets were identified. The figure shows the number of octamer sequences. Classification into the Y and TATA groups were done based on distribution profiles as shown in Figure 5. The REG group has a peak position between $-5 \mathrm{I}$ and -200 . 


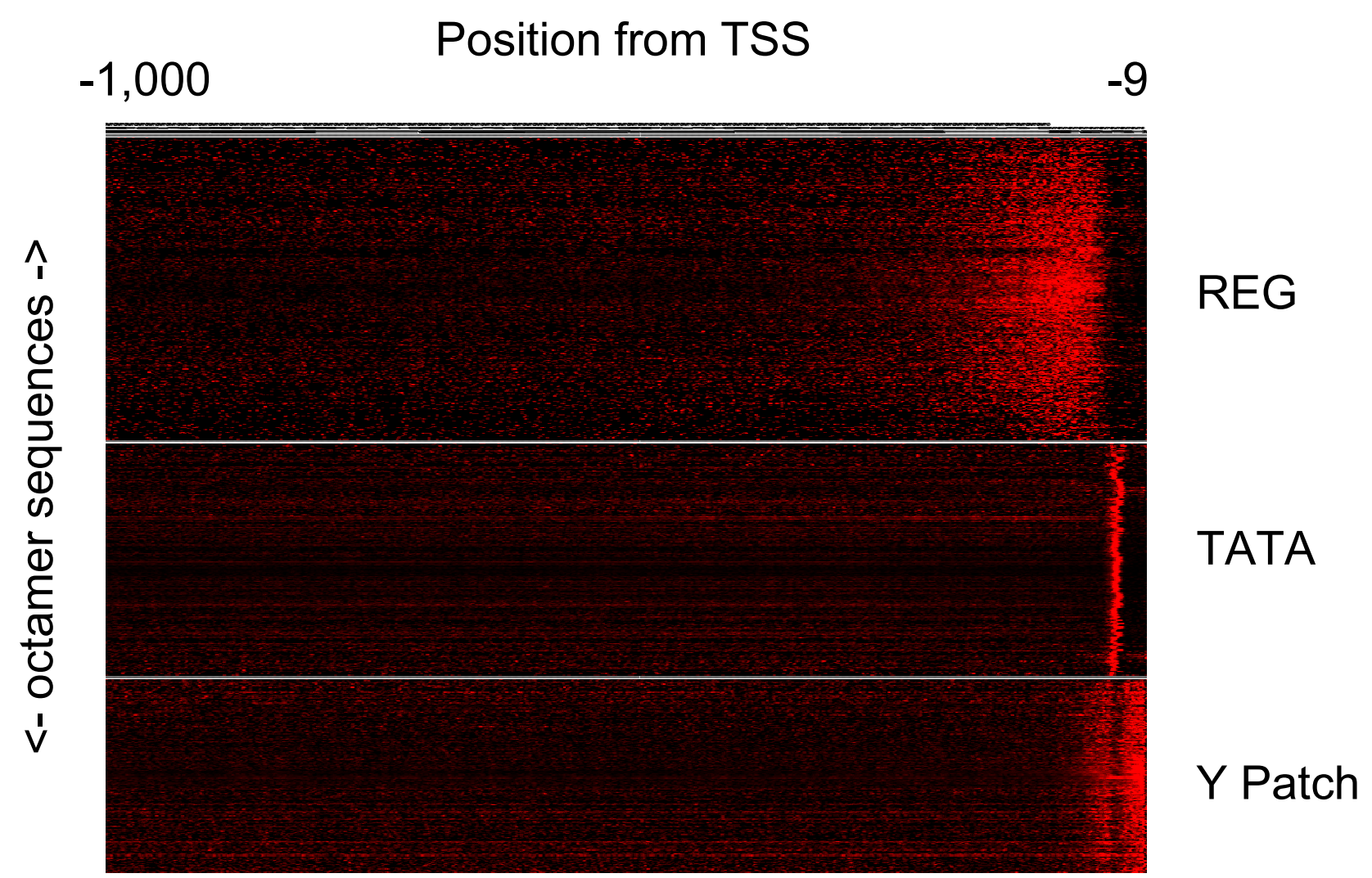

Figure 5

Clustering of LDSS-positive sequences based on distribution profiles. Distribution profiles of each LDSS-positive octamer of Arabidopsis were subjected to hierarchical clustering. Three major clusters are shown.

because cis-elements for light response (G-box: CACGTG, [36]) and stress response (ABRE: ACGTGTC, [39]) are related sequences both of which belong to the ACGT motif for environmental responses (Group 2, Table 3). Therefore, clustering of promoters appears reasonable, although the accuracy may not be enough for pinpoint speculation of gene function.

Clustering of REGs turned out to be reliable as well, and thus useful for REG classification. According to this 2D method, overlapping REGs (e.g., CACGTGGA and ACGTGGAT, Fig. 6C) have a bias toward coexistence by chance. However, similar but mutually exclusive sequences (e.g., ACGTGGAT and ACGTGGAA, Fig. 6C) are also clustered into the same group, suggesting that REGs with the same role are clustered together. This is explained by existence of multiple copies of the same kind of a cis-element in a promoter as different octamer expression. Figure 7 shows the whole tree of Arabidopsis REGs. This figure demonstrates that REGs with related sequences are clustered together with high reliability. According to these results, 12 motifs have been extracted from Arabidopsis REGs (Fig. $7)$, and are summarized in Table 3.

One group has a GGCCCA core sequence that is known as Site IIa or Element II (Group 1, Table 3). Element II is necessary for cell cycle-related expression and for meristematic expression [35]. Many sequences containing GGCCCA in the center of an octamer were found in REG group of both Arabidopsis and rice (Table 4). As seen in the table, this group is a good indicator of conservation.

Another group shown in the table has the bZIP proteinbinding motif containing ACGT core sequence. This group mediates various environmental signals [36]. Both species have this group in common, but Arabidopsis has wider variations than rice (Table 4 ).

Classification of Arabidopsis and rice REGs are shown in Table 3. The largest group is the Group 1, which includes 


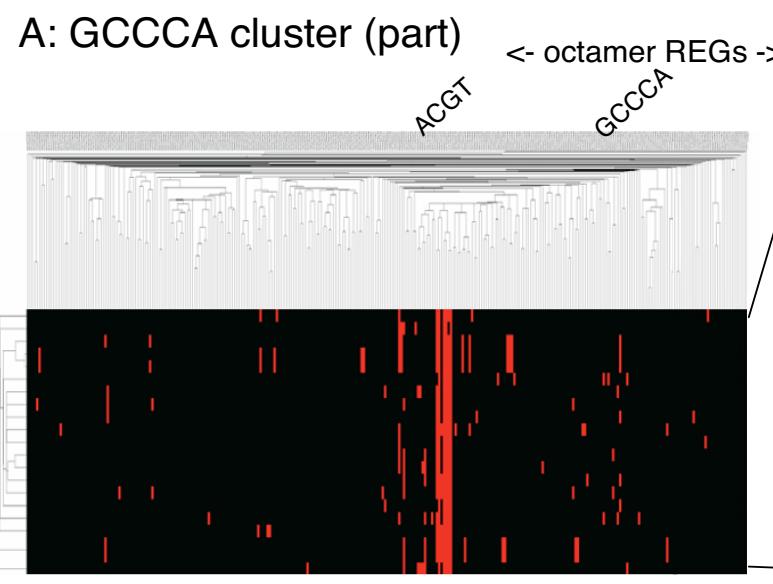

\section{promoters}

At3G25920 50S (plastid) ribosomal protein CL15 At5g22950 SNF7 family protein At4g17390 60S ribosomal protein L15 3_4_0_63

At4g17410 unknown protein

At1g02130 Ras-related protein (ARA5)

At5g17870 plastid-specific ribosomal protein At2g44310 EF-hand family protein At5g54920 unknown protein

3_1_1_147

At5g13730 SigD

At5g35400 tRNA pseudouridine synthase family protein

3_2_0_35

At1g15860 unknown protein

At5g15200 40 S ribosomal protein S9

At1957860 60S ribosomal protein L21

3_1_1_9

A

At3g56030 PPR repeat-containing protei

At4g05020 unknown protein

At4910960 UDP-glucose 4-epimerase activity

3_4_1_24

At1909350 galactinol synthase, putative

At1 g52230 Photosystem I PSI-H
At1g52220 Photosystem I PSI-P

At3g17810 dihydroorotate dehydrogenase family protein

At1g75460 ATP-dependent LON protease

At5g50101 unknown protein

At5g60890 receptor-like kinase ATR1, MYB34

At1g28530 unknown protein

At5g66580 unknown protein

At2g15970 cold-acclimation protein, putative

At1g10960 ferredoxin precursor isolog

At2g34451 HMG protein, putative

At5g47550 unknown protein

At3g53040 LEA protein, putative

At1906680 photosystem II OEC

At5g14780 formate dehydrogenase FDH

At5g61530 unknown protein

At1g06110 F-box family protein

At5g15840 zinc finger protein CONSTANS (CO)

3_5_0_27

At1g75440 uniquitin-conjugating enzyme 16 (UBC16)

At1g07600 matallothionein-like protein $1 \mathrm{~A}$

At1g07590 pentatricopeptide repeat-containing protain

At2g36630 unknown protein

3.4047

At5g51020 unknown protein

At1g29310 protein ptransport protein sec61, putative

At1g31230 aspartate kinase-homoserine dehydrogenase like

At1g73860 kinesin-related protein

At4g28750 photosystem I PSAE 1

At1g21780 unknown protein

At1g35720 Ca2+-dependent membrane-binding annexin

At1955520 transcription initiation factor TFIID-2/TBP2

At1 771960 ABC transporter family protein

At1g22510 C3HC4-type RING finger protein

At4g32760 unknown protein

At4g24795 unknown protein

At3g20250 RNA-binding protein, putative

At5g63160 unknown protein

At5g14500 unknown protein

C: REG cluster (ACGT, part)

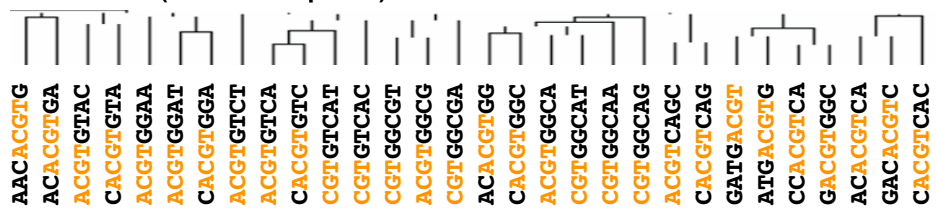

Figure 6

REG-promoter clustering. For each Arabidopsis promoter, number of each octamer REG within a region from -400 to -40 bp was scored, and subjected to 2D hierarchical clustering. The vertical axis shows promoters and the horizontal axis does REGs. The matrix means number of REG sequences. Two small promoter clusters are shown in the figure together with the whole REGs. (A) A part of promoter cluster rich in GCCCA motif for meristematic expression. Ribosomal proteins are shown in blue. (B) A part of promoter cluster rich in ACGT motif for environmental response. Promoter names are expressed in color according to expression data from AtGenExpress. Red: abiotic stress-positive, orange: abiotic stress-negative, green: light-positive, black: no response to abiotic stress or light, grey: no expression data found. (C) An example of clustered REGs. A part of the ACGT cluster shown in the top of Panel A is enlarged. ACGT in the octamers are highlighted with orange. 


\begin{tabular}{|c|c|c|c|c|c|c|c|c|c|}
\hline Group & Motifl & Motif name & Comment & Trans factor & Expression & Reference & $A t^{\prime}$ & Ricel $^{\prime}$ & At \& Rice ${ }^{2}$ \\
\hline I & GCCCA & $\begin{array}{l}\text { Element II of Arabidopsis PCNA-2, } \\
\text { Site Ila of rice PCNA }\end{array}$ & & PCFI, PCF2, TCP20 & $\begin{array}{l}\text { cell cycle/meristematic } \\
\text { expression }\end{array}$ & {$[35,60]$} & 36 & 68 & 71 \\
\hline 2 & ACGT & "ACGT Core", G-box, ABRE, & & bZIP family (GBF, TGAI, etc.), PIF3 & $\begin{array}{l}\text { environmental response (light, } \\
\text { UV, drought, ABA) }\end{array}$ & {$[36,61]$} & 33 & 4 & 9 \\
\hline 3 & ACGCGC & CGCG box & & AtSRI(CaMBP) & stress response? & [62] & 7 & I & 0 \\
\hline 4 & CCGAC & DRE & DRE core & DREB/CBF & stress response & [39] & 9 & 3 & 0 \\
\hline 5 & $\operatorname{AACCG}(\mathrm{G} / \mathrm{A})$ & novel & $\begin{array}{l}\text { overlapping with GTI } \\
\text { box (TTAACC) }\end{array}$ & $?$ & not known & this study & 36 & I & 0 \\
\hline 6 & $\mathrm{AAACG}(\mathrm{C} / \mathrm{G})$ & novel & & ? & not known & this study & 13 & । & 2 \\
\hline 7 & АССCCT & novel & & ? & not known & this study & 4 & 0 & 0 \\
\hline 8 & АCCCT & novel & & ? & not known & this study & 4 & 0 & 0 \\
\hline 9 & ACGGGC & novel & & ? & not known & this study & 2 & 5 & I \\
\hline 10 & CCATGG & novel & & ? & not known & this study & 1 & I & 2 \\
\hline 11 & CCAACGG & novel & & $?$ & not known & this study & 1 & 4 & 6 \\
\hline 12 & GGGACCC & novel & & ? & not known & this study & 4 & 3 & 4 \\
\hline Rest & & & & & & & 74 & 66 & I \\
\hline Total & & & & & & & 308 & 242 & 90 \\
\hline 'Numbe & $r$ of octamer sec & ences. This classification is not comp & ly mutually exclusive. & & & & & & \\
\hline
\end{tabular}




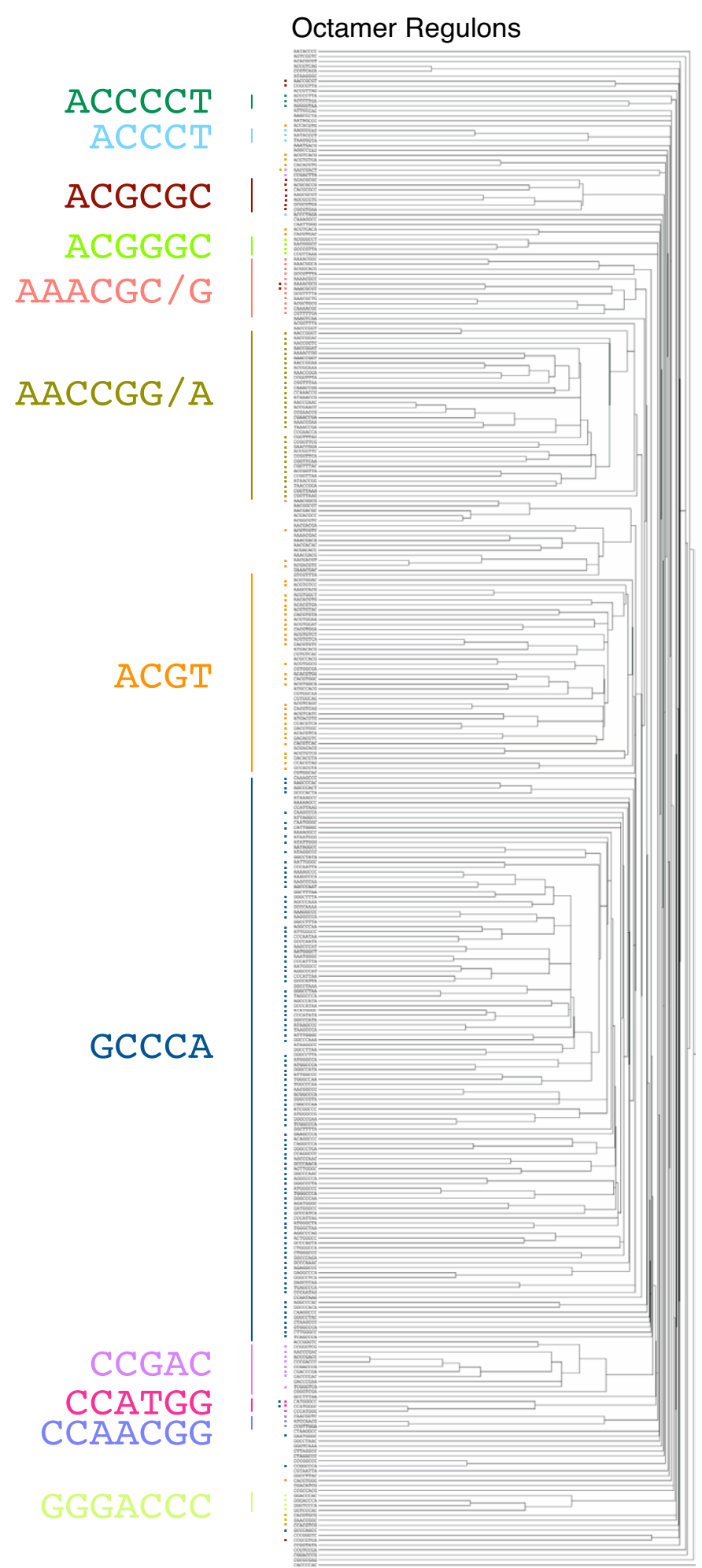

\section{Figure 7}

Clustering of REGs. Aided by REG-promoter clustering, Arabidopsis REGs were subjected to classification. Colored dots in the figure mean presence of the corresponding motif in the REG sequence. The tree is the same as one in Figure 6A. 
Table 4: Several REG groups were identified from Arabidopsis and rice octamer analysis

\begin{tabular}{|c|c|}
\hline Arabidopsis & Rice \\
\hline \multicolumn{2}{|l|}{$*$ GGCCCA* } \\
\hline AGGCCCAA\# & AGGCCCAA\# \\
\hline AGGCCCAC\# & AGGCCCAC\# \\
\hline AGGCCCAG\# & AGGCCCAG\# \\
\hline AGGCCCAT\# & AGGCCCAT\# \\
\hline CGGCCCAA\# & CGGCCCAA\# \\
\hline CGGCCCAT\# & CGGCCCAC \\
\hline GGGCCCAA\# & CGGCCCAG \\
\hline GGGCCCAG\# & CGGCCCAT\# \\
\hline GGGCCCAT\# & GGGCCCAA\# \\
\hline TGGCCCAA & GGGCCCAC \\
\hline TGGCCCAG\# & GGGCCCAG\# \\
\hline \multirow[t]{4}{*}{ TGGCCCAT\# } & GGGCCCAT\# \\
\hline & TGGCCCAC \\
\hline & TGGCCCAG\# \\
\hline & TGGCCCAT\# \\
\hline \multicolumn{2}{|c|}{$* * \mathrm{ACGT}^{* *}, * \mathrm{ACG} \mathrm{T}^{* * * *}$} \\
\hline ACACGTCA & ACACGTGG\# \\
\hline ACACGTGA & CACGTCAC\# \\
\hline ACACGTGG\# & CACGTCTC \\
\hline CACGTCAC\# & CACGTGGC\# \\
\hline CACGTCAG & CACGTGGG\# \\
\hline CACGTCAT & CACGTGTC\# \\
\hline \multicolumn{2}{|l|}{ CACGTCTC\# } \\
\hline \multicolumn{2}{|l|}{ CACGTGAC } \\
\hline \multicolumn{2}{|l|}{ CACGTGCG } \\
\hline \multicolumn{2}{|l|}{ CACGTGGA } \\
\hline \multicolumn{2}{|l|}{ CACGTGGC\# } \\
\hline \multicolumn{2}{|l|}{ CACGTGGG\# } \\
\hline \multicolumn{2}{|l|}{ CACGTGGT } \\
\hline \multicolumn{2}{|l|}{ CACGTGTA } \\
\hline \multicolumn{2}{|l|}{ CACGTGTC\# } \\
\hline \multicolumn{2}{|l|}{ CACGTGTG } \\
\hline \multicolumn{2}{|l|}{ CACGTGTT } \\
\hline \multicolumn{2}{|l|}{ CCACGTAG } \\
\hline \multicolumn{2}{|l|}{ CCACGTCA } \\
\hline \multicolumn{2}{|l|}{ CCACGTCG } \\
\hline GACGTCGT & \\
\hline
\end{tabular}

REGs found in both Arabidopsis and rice are indicated with a sharp (hash) symbol. An asterisk indicates any base and is used to restrict the position of the motif in the octamer sequence.

Element II of the Arabidopsis PCNA-2 involved in cell cycle-related expression, as mentioned above. As shown in the table, this group is well conserved between Arabidopsis and rice and has many members for both species. There are several other REG groups, some of which are rich in only Arabidopsis and some are found from both (several examples in Table 4 and summarized in Table 3 ). Comparison between Arabidopsis and rice suggests both conserved and differentiated types of REGs.

The identified Arabidopsis REG sequences were referred to the PLACE database that is a collection of reported plant cis-regulatory elements [40]. The comparison revealed that 155 out of 308 Arabidopsis REGs show $100 \%$ match with at least one of the Arabidopsis PLACE entries, giving an estimation that $50 \%$ of the REGs are of established cisregulatory elements (Table S6 [see Additional file 7]). These results again provide strong evidence for biologically meaningful extraction of sequences by the LDSS method. From another point of view, 21 out of 48 Arabidopsis PLACE entries have been found in the REG list (Table 5). Comparison with another cis-element database, AGRIS [41], resulted in lower match than PLACE (27\%) among Arabidopsis motif entries shorter than 9 bps (data not shown). These results suggest that not all of the cis-regulatory elements are detected by the LDSS strategy. One of the valuable finding of this analysis is the identification of a large number of novel REGs.

\section{Characterization of transcription start site}

We then analyzed sequence characteristics around the TSS. In this region, the Initiator motif (Inr: YYAN(T/A)YY, TSS is underlined) is known in some mammalian promoters [1], and it is also functional in plants [42]. A survey of Arabidopsis TSS revealed that a limited number of promoters (less than 10\%) have the Inr motif around the TSS. Thus, we looked for a more general rule. We surveyed which base is preferred at the $-1 /+1$ position among Arabidopsis TSS. The most frequently observed sequence was C $\underline{\text { A }}$ (TSS is underlined), and Ta was the second. As summarized in Figure 8A, there is a strong preference of a dimer sequence at the $-1 /+1$ position. The graph clearly shows most of the TSS is A or G, and the -1 position is likely to be $\mathrm{C}$ or T. This "YR Rule" (YR, TSS underlined, Y: C or T, R: A or G) applies to as many as $77 \%$ of the Arabidopsis promoters that is a much higher frequency than expected random appearance $(25 \%)$. Similar analysis for the $-2 /-1$ and $+1 /+2$ positions did not reveal clear extension of the rule. When the YR Rule was applied to the $-6 /$ -5 to $+4 /+5$ positions, we found that the ratio of YR Rulepositive is highest at the $-1 /+1$ position in the local region examined (Fig. 8B, Arabidopsis). The figure shows that this rule is also applicable to rice TSS (Fig. 8B, rice). These analyses have revealed that sequence preference at TSS is well conserved between Arabidopsis and rice.

\section{An example of Arabidopsis promoter}

Our simple LDSS analysis has successfully revealed three distinct groups consisting of hundreds of short sequences. Figure 9A illustrates the architecture of plant promoters based on these findings.

Tight positioning of the TATA boxes relative to the TSS fits with the general idea that the TATA boxes determine the position of the TSS. In addition, the YR Rule of Arabidopsis would be another important determinant as well. The Y Patches locate between the TATA boxes and the TSS, but 
Table 5: PLACE cis-elements found and not found in Arabidopsis REGs

\section{PLACE discription}

sequence

\begin{tabular}{|c|c|}
\hline nd & \\
\hline I & $\begin{array}{l}\text { ACGTATERDI ACGT sequence required for etiolation-induced expression of erd I (early responsive to dehydration) } \\
\text { in Arabidopsis; }\end{array}$ \\
\hline 2 & $\begin{array}{l}\text { ABRELATERDI ABRE-like sequence (from - } 199 \text { to -195) required for etiolation-induced expression of erd I (early } \\
\text { responsive to dehydration) in Arabidopsis; }\end{array}$ \\
\hline 3 & LTRECOREATCOR I 5 Core of low temperature responsive element (LTRE) of cor I5a gene in Arabidopsis; \\
\hline 4 & $\begin{array}{l}\text { SORLIP IAT one of "Sequences Over-Represented in Light-Induced Promoters (SORLIPs) in Arabidopsis; } \\
\text { Computationally identified phyA-induced motifs; }\end{array}$ \\
\hline 5 & $\begin{array}{l}\text { SORLIP2AT one of "Sequences Over-Represented in Light-Induced Promoters (SORLIPs) in Arabidopsis; } \\
\text { Computationally identified phyA-induced motifs; }\end{array}$ \\
\hline 6 & $\begin{array}{l}\text { WBOXATNPRI "W-box" found in promoter of Arabidopsis NPRI gene; They were recognized specifically by } \\
\text { salicylic acid (SA)-induced WRKY DNA binding proteins; }\end{array}$ \\
\hline 7 & CACGTGMOTIF "CACGTG motif"; "G-box; Binding site of Arabidopsis GBF4; \\
\hline 8 & $\begin{array}{l}\text { YB2CONSENSUSAT MYB recognition site found in the promoters of the dehydration-responsive gene } r d 22 \text { and } \\
\text { any other genes in Arabidopsis; } Y=C / T ; K=G / T ;\end{array}$ \\
\hline 9 & $\begin{array}{l}\text { MYBCORE Binding site for all animal MYB and at least two plant MYB proteins ATMYBI and ATMYB2, both isolated } \\
\text { from Arabidopsis; ATMYB2 is involved in regulation of genes that are responsive to water stress in Arabidopsis; }\end{array}$ \\
\hline 10 & $\begin{array}{l}\text { SITEIIATCYTC "Site II element" found in the promoter regions of cytochrome genes (Cytc-I, Cytc-2) in Arabidopsis; } \\
Y=C / T \text {; }\end{array}$ \\
\hline II & $\begin{array}{l}\text { ACGTABREMOTIFA2OSEM Experimentally determined sequence requirement of ACGT-core of motif } A \text { in } A B R E \\
\text { of the rice gene, OSEM; DRE and ABRE are interdependent in the ABA-responsive expression of the rd } 29 A \text { in } \\
\text { Arabidopsis; } K=G / T \text {; }\end{array}$ \\
\hline 12 & $\begin{array}{l}\text { DPBFCOREDCDC3 A novel class of bZIP transcription factors, DPBF-I and } 2 \text { (Dc3 promoter-binding factor-I and 2) } \\
\text { binding core sequence; Found in the carrot Dc3 gene promoter; Dc3 expression is normally embryo-specific, and also } \\
\text { can be induced by ABA; The Arabidopsis abscisic acid response gene ABI5 encodes a bZIP transcription factor; abi5 } \\
\text { mutant have a pleiotropic defects in ABA response; ABI5 regulates a subset of late embryogenesis-abundant genes; GIAI }\end{array}$ \\
\hline
\end{tabular}

13 GADOWNAT Sequence present in 24 genes in the GA-down regulated dI cluster found in Arabidopsis seed germination;

14 WUSATAg Target sequence of WUS in the intron of AGAMOUS gene in Arabidopsis;

15 CDAIATCAB2 CDA-I (CAB2 DETI-associated factor I) binding site in DtRE (dark response element) $f$ of chlorophyll a/b-binding protein2 (CAB2) gene in Arabidopsis;

16 EMBPITAEM Binding site of trans-acting factor EMBP-I; wheat Em gene; Binding site of ABFs; ABFs (ABRE binding factors) were isolated from Arabidopsis by a yeast one-hybrid screening system; Involved in ABA-mediated stresssignaling pathway;

17 HEXAT "Hex motif" ; Binding site of Arabidopsis bZIP protein TGAI and G box binding factor GBFI; G-Box-like element;

I8 UPRMOTIFIAT "Motif I" in the conserved UPR (unfolded protein response) cis-acting element in Arabidopsis genes coding for SARIB, HSP-90, SBR-like, Ca-ATPase 4, CNXI, PDI, etc.;

19 RAVIAAT Binding consensus sequence of Arabidopsis transcription factor, RAVI; The expression level of RAVI were relatively high in rosette leaves and roots;

20 DRECRTCOREAT Core motif of DRE/CRT (dehydration-responsive element/C-repeat) cis-acting element found in many genes in Arabidopsis and in rice; $R=G / A$;

2I ELRECOREPCRP I EIRE (Elicitor Responsive Element) core of parsley (P.c.) PRI genes; consensus sequence of elements WI and W2 of parsley PRI-I and PRI-2 promoters; Box WI and W2 are the binding site of WRKYI and WRKY2, respectively; W-box found in thioredoxin h5 gene in Arabidopsis (Laloi et al.);

not

ARRIAT"ARRI-binding element" found in Arabidopsis; ARRI is a response regulator; $N=G / A / C / T$;

ARFAT ARF (auxin response factor) binding site found in the promoters of primary/early auxin response genes of Arabidopsis; AuxRE; Binding site of Arabidopsis ARFI (Auxin response factorl); of rbcS of tomato and Arabidopsis;

26 MYBIAT MYB recognition site found in the promoters of the dehydration-responsive gene $r d 22$ and many other genes in Arabidopsis; $W=A / T$;

27 MYB2AT Binding site for ATMYB2, an Arabidopsis MYB homolog; ATMYB2 is involved in regulation of genes that are responsive to water stress in Arabidopsis;

28 MYCATERD I MYC recognition sequence necessary for expression of erd I (early responsive to dehydration) in dehydrated Arabidopsis; NAC protein bound specifically to the CATGTG motif (Tran et al., 2004);

29 MYCATRD22 Binding site for MYC (rd22BPI) in Arabidopsis dehydration-responsive gene, rd22; MYC binding site in rd22 gene of Arabidopsis; ABA-induction;

ACGT

ACGTG

CCGAC

GCCAC

GGGCC

TTGAC

CACGTG

YAACKG

CNGTTR

TGGGCY

ACGTGKC

ACACNNG

ACGTGTC

TTAATGG

CAAAACGC

CACGTGGC

TGACGTGG

CCACGTCA

CAACA

RCCGAC

TTGACC

NGATT

TGTCTC

CCGTCG

GATAAG

WAACCA

TAACTG

CATGTG

CACATG 
Table 5: PLACE cis-elements found and not found in Arabidopsis REGs (Continued)

\begin{tabular}{|c|c|c|}
\hline 30 & $\begin{array}{l}\text { PREATPRODH "PRE (Pro- or hypoosmolarity-responsive element) found in the promoter region of proline } \\
\text { dehydrogenase (ProDH) gene in Arabidopsis; }\end{array}$ & ACTCAT \\
\hline 31 & $\begin{array}{l}\text { RAVIBAT Binding consensus sequence of an Arabidopsis transcription factor, RAVI; The expression level of RAVI } \\
\text { were relatively high in rosette leaves and roots; }\end{array}$ & CACCTG \\
\hline 32 & $\begin{array}{l}\text { SREATMSD "sugar-repressive element (SRE)" found in } 272 \text { of the } 1592 \text { down-regulated genes after main stem } \\
\text { decapitation in Arabidopsis; }\end{array}$ & TTATCC \\
\hline 33 & $\begin{array}{l}\text { TBOXATGAPB "Tbox" found in the Arabidopsis GAPB gene promoter; Mutations in the "Tbox" resulted in } \\
\text { reductions of light-activated gene transcription; }\end{array}$ & ACTTTG \\
\hline 34 & $\begin{array}{l}\text { AGCBOXNPGLB "AGC box" repeated twice in a } 6 \text { I bp enhancer element in tobacco (N.p.) class I beta-I,3-glucanase } \\
\text { (GLB) gene; "GCC-box"; Binding sequence of Arabidopsis AtERFs; }\end{array}$ & AGCCGCC \\
\hline 35 & $\begin{array}{l}\text { GAREAT GARE (GA-responsive element); Occurrence of GARE in GA-inducible, GA-responsible, and GA- } \\
\text { nonresponsive genes found in Arabidopsis seed germination was } 20,18 \text {, and I } 2 \% \text {, respectively; }\end{array}$ & TAACAAR \\
\hline 36 & LEAFYATAG Target sequence of LEAFY in the intron of AGAMOUS gene in Arabidopsis; & CCAATGT \\
\hline 37 & $\begin{array}{l}\text { LTREATLTI78 Putative low temperature responsive element (LTRE); Found in Arabidopsis low-temperature-induced } \\
\text { (Iti) genes, Iti78/cor78/rd29A and Iti65; }\end{array}$ & ACCGACA \\
\hline 38 & $\begin{array}{l}\text { MYBATRD22 Binding site for MYB (ATMYB2) in dehydration-responsive gene, rd22; MYB binding site in rd22 gene of } \\
\text { Arabidopsis thaliana; ABA-induction; }\end{array}$ & CTAACCA \\
\hline 39 & $\begin{array}{l}\text { SORLIP5AT one of "Sequences Over-Represented in Light-Induced Promoters (SORLIPs) in Arabidopsis; } \\
\text { Computationally identified phyA-induced motifs; }\end{array}$ & GAGTGAG \\
\hline 40 & $\begin{array}{l}\text { ABREZMRAB28 ABRE; ABA and water-stress responses; Found in maize (Z.m.) rab28; maize rab28 is ABA-inducible } \\
\text { in embryos and vegetative tissues; Found in the Arabidopsis alcohol dehydrogenase (Adh) gene promoter; }\end{array}$ & CCACGTGG \\
\hline 41 & $\begin{array}{l}\text { CCAIATLHCB I CCAI binding site; CCAI protein (myb-related transcription factor) interact with two imperfect } \\
\text { repeats of AAMAATCT in LhcbI*3 gene of Arabidopsis; Related to regulation by phytochrome; }\end{array}$ & AAMAATCT \\
\hline 42 & $\begin{array}{l}\text { E2FANTRNR "E2Fa element" found in the tobacco RNR (Ribonucleotide reductase) gene promoter and in the } \\
\text { Arabidopsis CDC6 gene promoter; Binding site of tobacco and Arabidopsis E2F; Involved in upregulation of the } \\
\text { promoter at GI/S transition; }\end{array}$ & TTTCCCGC \\
\hline 43 & LIBOXATPDFI "LI box" found in promoter of Arabidopsis PROTODERMAL FACTORI (PDFI) gene; $Y=\mathrm{C} / \mathrm{T}$; & TAAATGYA \\
\hline 44 & $\begin{array}{l}\text { OCTAMERMOTIFTAH3H4 "Octamer motif" found in promoter of wheat histone genes } \mathrm{H} 3 \text { and } \mathrm{H} 4 \text {, and corn } \\
\text { histone genes } \mathrm{H} 3 \text { and } \mathrm{H} 4 \text {; Arabidopsis histone H4; "histone-specific octamer"; }\end{array}$ & CGCGGATC \\
\hline 45 & $\begin{array}{l}\text { PIATGAPB "PI" found in the Arabidopsis GAPB gene promoter; Mutations in the "PI" resulted in reductions of light- } \\
\text { activated gene transcription; }\end{array}$ & GTGATCAC \\
\hline 46 & $\begin{array}{l}\text { RYREPEATVFLEB4 "RY repeat motif"; quantitative seed expression; Gene: Vicia faba LeB4; Soybean glycinin (Gy2); } \\
\text { other dicot and monocot seed protein genes; Binding site of Arabidopsis B3-domain-containing transcription factor } \\
\text { FUS3; }\end{array}$ & CATGCATG \\
\hline 47 & $\begin{array}{l}\text { UP2ATMSD "Up2" motif found in } 193 \text { of the } 1184 \text { up-regulated genes after main stem decapitation in Arabidopsis; W } \\
\text { = A/T; }\end{array}$ & AAACCCTA \\
\hline 48 & $\begin{array}{l}\text { ZDNAFORMINGATCAB I "Z-DNA-forming sequence" found in the Arabidopsis chlorophyll a/b binding protein } \\
\text { gene (cabI) promoter; Involved in light-dependent developmental expression of the gene; "Z-box"; }\end{array}$ & ATACGTGT \\
\hline
\end{tabular}




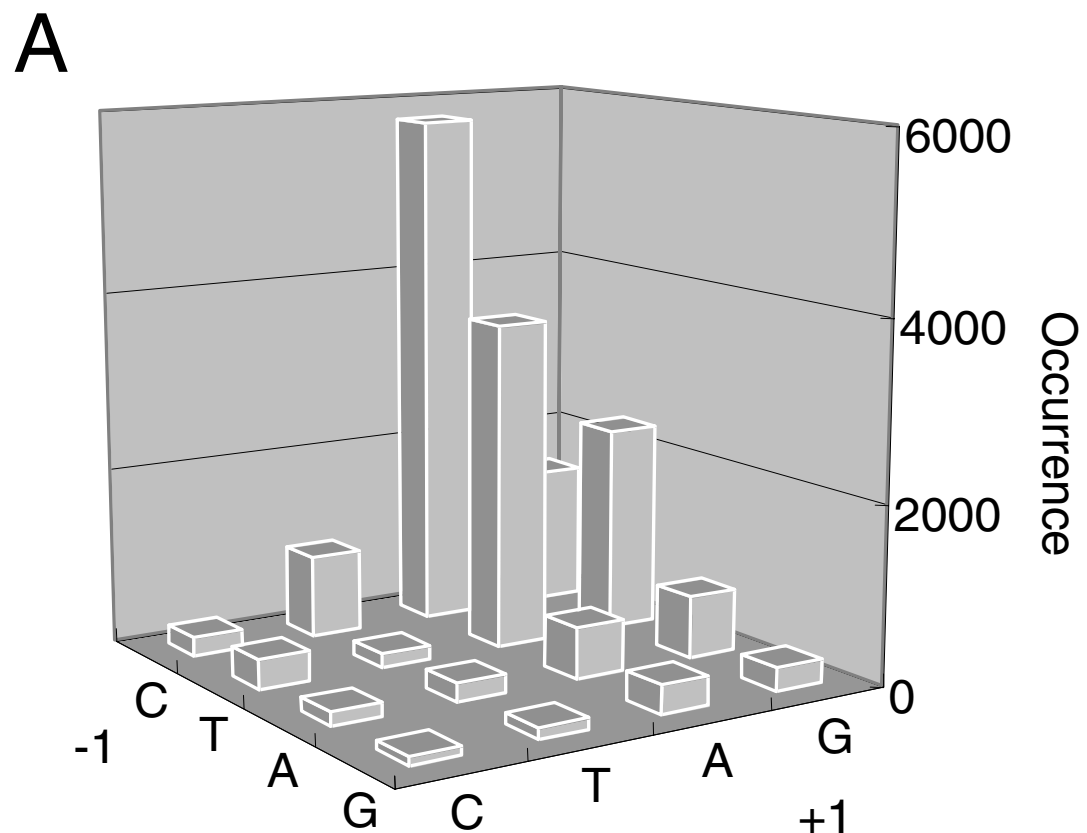

B

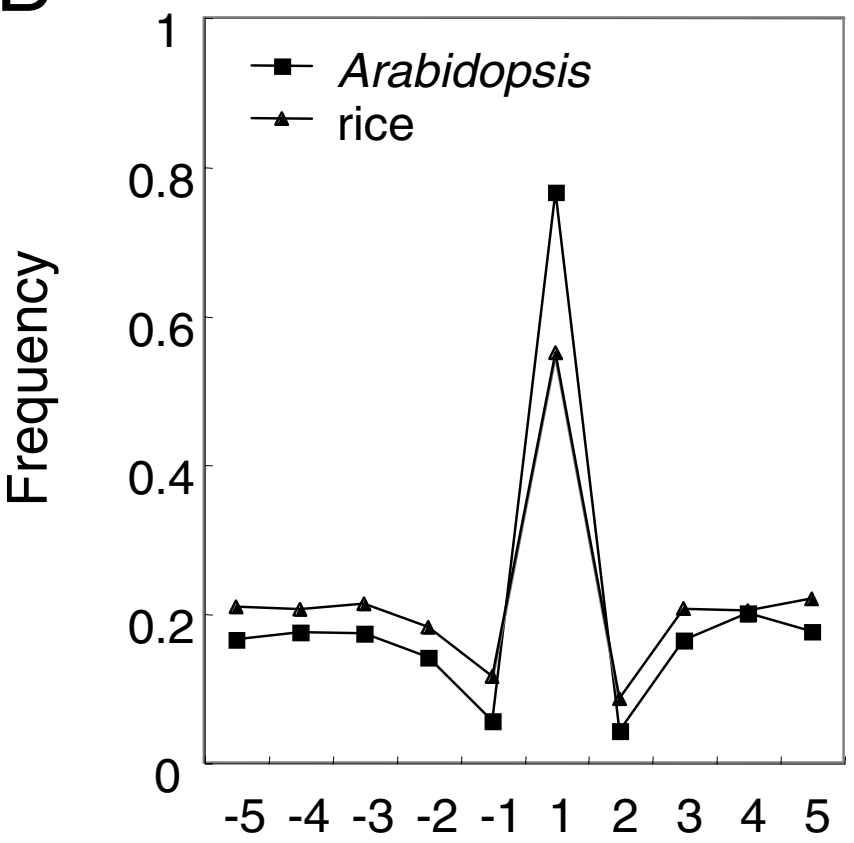

\section{Position from TSS}

\section{Figure 8}

Identification of YR Rule. (A) Dinucleotide sequences at the $-1 /+1$ position relative to Arabidopsis TSS, determined by information of the fl-cDNAs, were counted. As shown, most of the TSS have (C/T)(A/G), and this YR Rule applies to $77 \%$ of the analyzed TSSs. (B) Frequency of dinucleotide sequences fitting with YR Rule was scanned from -5 to +5 of Arabidopsis and rice TSS. Position of the downstream site of the dimer is shown. For example, the $-\mathrm{I} /+\mathrm{I}$ position is indicated as "I". Theoretically frequency of $Y R$ in non-biased sequence is 0.25 . 


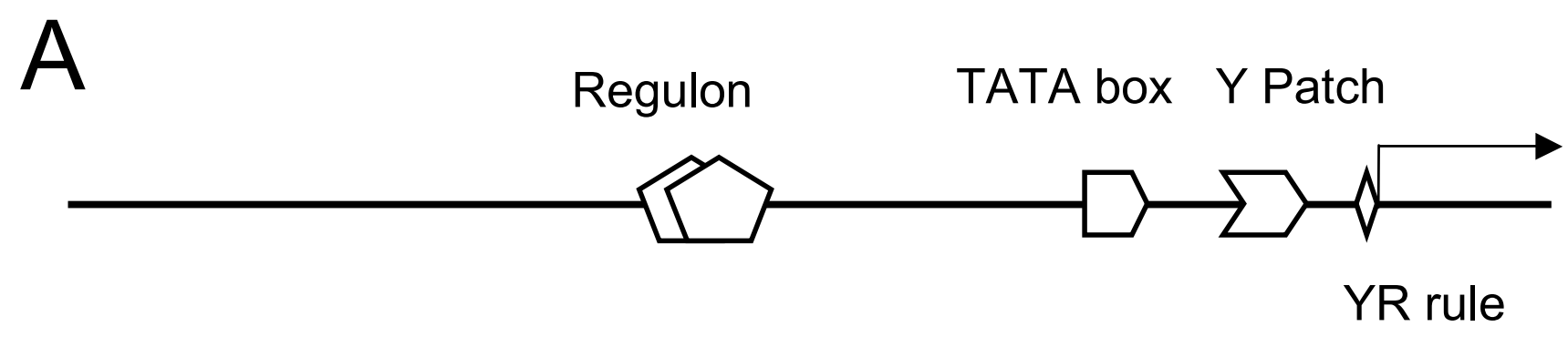

B

Atlg10960 ferredoxin precursor isolog

$-100$

CATAGAGACAATCACCAAGAAGATAACACAAGAGCCCACACATCG
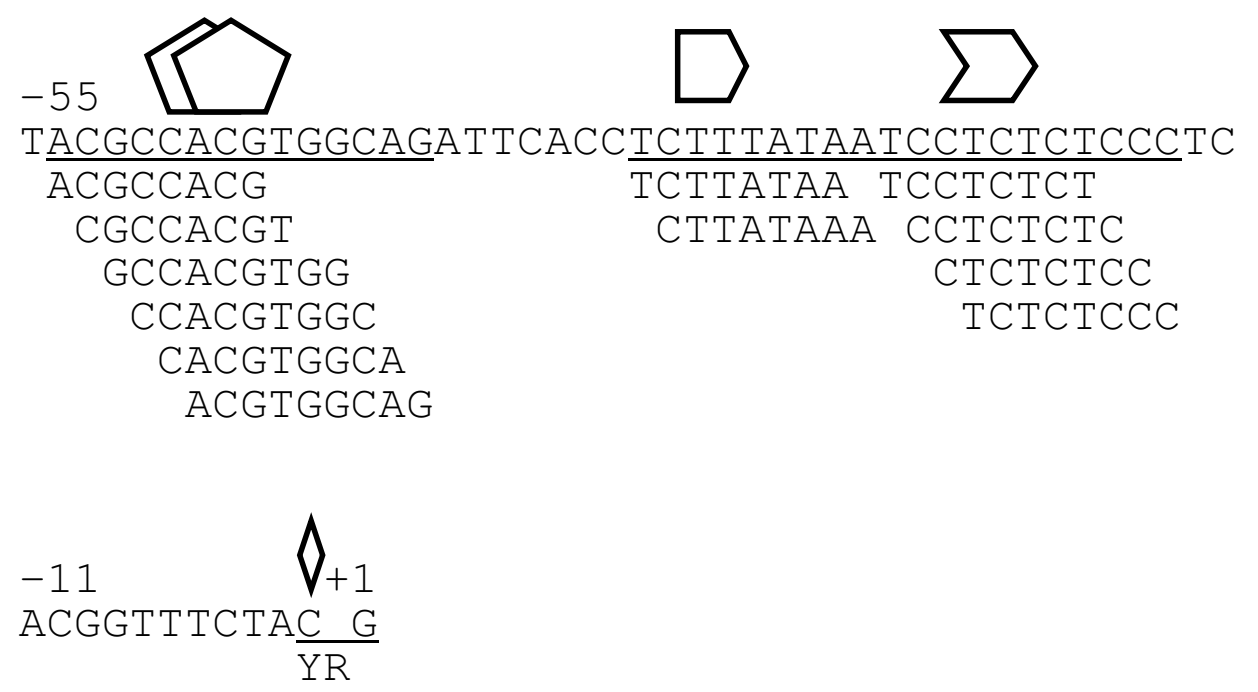

Figure 9

Illustration of YR Rule, Y Patch, TATA box, and REG. (A) Expected appearance positions relative to the TSS are as follows: YR Rule (-1/+I), Y Patch (-100 to - I), TATA box (-50 to -20), REG $(-20$ to -400$)$. Among them, only the REG is orientation-insensitive, and the other groups are sensitive. In many cases the $Y$ Patch locates between the TATA boxes and the TSS, but it is also observed upstream of the TATA boxes. (B) An example of an Arabidopsis promoter that has a Y Patch and TATA box. At lg 10960 is one of the promoters clustered in Figure 6B. The promoter sequence from -100 to $+I$ is shown together with octamer motifs. Marks on the sequence are the same as illustrated in (A). 
they can be upstream of the TATA boxes, considering the wide distribution profiles (Figure 5). The role of the Y Patch is not known. The above three elements are orientation-sensitive, and constituents of a core promoter. REGs appear upstream of the TATA box, and they exist in an orientation-insensitive manner. Rice promoters share the above characteristics, showing architectural conservation between dicots and monocots.

An example of an Arabidopsis promoter that has the $\mathrm{Y}$ Patch and TATA box is shown in Figure 9B. Octamer analysis of the promoter revealed one cluster of Group 2 REGs (Table 3), one cluster of Y Patches, one cluster of TATA box, and YR Rule. An interesting feature of the figure is the multiple hits of a locus, detecting a longer element. This demonstrates that octamer analysis can detect long functional units as clusters of octamers.

\section{Discussion \\ Characteristics of LDSS analysis}

In this study, we have identified hundreds of novel sequences solely based on local distribution in the promoter region of Arabidopsis and rice. Biological information, such as microarray data, was not used at all for sequence extraction, and it becomes useful only during interpretation of the extracted sequence. This method is equally sensitive in detection of major and minor motifs in a promoter population as demonstrated by simultaneous detection of major TATA elements and minor REG elements. This feature is an advantage of the LDSS method over other methods of detection of consensus sequences among promoter populations, such as Gibbs Sampling method. We successfully applied the LDSS method to Arabidopsis and rice promoters, and of course, it is applicable to bacterial and mammalian research as well.

The observed localized distribution is a direct result of the selection pressure. While the localization is an indication of a beneficial role for the organism, the relationship between local distribution of a sequence and its functionality is indirect. Therefore, the question arises if all regulatory elements can be picked up by the LDSS strategy.

When we compared REG sequences with established ciselements in the PLACE database, it was found that 27 out of 48 Arabidopsis PLACE entries are absent in the extracted REGs (Table 5). These results indicate that not all of the functional elements are LDSS-positive, and thus some would not be detected by this method. There are two possibilities for the presence of cis-elements that do not show local distribution. One possibility is that these elements are relatively "new" so there has not been selection pressure for a long enough period. Another possibility is that there has not been any selection pressure because of functional differences from the LDSS-positive elements. The latter idea suggests localization-insensitive classes of regulatory elements that are distinct from REGs. So called long range-regulators $[43,44]$ might be one of the classes.

Generally, any functional sequences in the genome are recognized by trans-acting factors that are DNA-binding proteins. Promoter elements and their trans-factors have a relationship of co-evolution. Therefore, differentiation of REGs in the two species would reflect a different status of the corresponding trans-factors. Functional comparison of DNA-binding proteins of Arabidopsis and rice is expected to give some answers as to why these two species have differentiated REG sequences. As for the conserved REGs, it is reasonable that cell cycle-related elements (Group 1, Table 3) comprise the most conserved group, because the cell cycle is one of the most conserved activities in organisms.

REG sequences can be extracted form mammalian promoters as well. However, our preliminary analyses suggest that the LDSS method can detect much less REGs than of plants (YYY and JO, unpublished results). This may be reflected by different promoter architecture between plants and animals.

\section{Y Patch}

The discovery that the Y Patch is conserved in monocots and dicots is one of the major achievements of this study. A related motif is reported by Molina and Grotewold from Arabidopsis core promoter analysis using the Gibbs-sampling method (Motif 1 with a typical sequence, TTCTTCTTC, [29]). The biochemical role of Y Patch is not known, but its position, direction sensitivity, and its abundant nature strongly suggest that it is a general component of the core promoter. Our LDSS analyses suggest that human and mouse do not share this element with plants and thus this is a plant-specific core element (YYY and $\mathrm{JO}$, unpublished results).

\section{YR Rule}

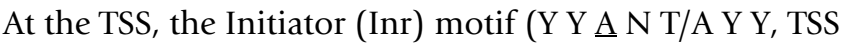
is underlined) is known as a recognition site by TFIID [3]. Following their rules, the YR Rule can be considered as a less stringent form of Inr. According to this point of view, the YR Rule might be recognized by TFIID. The high coverage of the YR Rule is a useful feature for prediction of TSS. Recently, Carninci et al., have reported the same rule is applicable to mouse and human promoters as well [45], revealing conservation of YR Rule between plants and mammals.

This rule is not an artifact by the Cap-Trapper method that is the basis of TSS mapping of this study and mammalian studies mentioned above [45], because it is applicable to 
human TSS determined by another method (Oligo-Cap method, [46]) as well (YYY and JO, unpublished results).

A plant consensus around TSS (A/T n T/a C/t A/c a/t, TSS is underlined) is reported by Shahmuradov et al based on 217 dicot promoters (actual consensus is expressed by a matrix, [47]). This consensus also largely overlaps with YR Rule.

The TFIIB-Recognition Element (BRE) is another core promoter element of animal genes. It is located just upstream of the TATA box and has a GC-rich sequence, $(\mathrm{G} / \mathrm{C})(\mathrm{G} /$ C)(G/C)CGCC $[1,48]$. Our analysis did not detect the BRE as a LDSS-positive element, although CC is preferred at the neighboring sequence of the TATA box at the upstream side in both Arabidopsis and rice promoters (Table S2 [see Additional file 3] and S3 [see Additional file 4]).

\section{LDSS analysis provides useful information toward precise promoter prediction}

The hundreds of octamer sequences identified by the LDSS analysis can be used for promoter prediction. The presence of the TATA box is an important feature of a promoter, but there are many false-positives in the genome. For example, a TATA octamer sequence with the highest specific localization is found within the peak area $30 \%$ of times in the promoter region, meaning that $70 \%$ are found outside of the peak area. This is essentially consistent with a previous study, where more than 200,000 putative TBP-binding sites were detected from the Arabidopsis genome [27]. Utilization of preferential sequence around the TATA box, and coexistence with the Y Patch and REG are expected to elevate accuracy of prediction. Although such a combinational approach is incorporated into several promoter prediction programs [13], motifs to be detected have been limited so far. Our long list of the LDSS-positive octamers is expected to serve as a thick dictionary for precise interpretation of plant genomes.

\section{Conclusion}

In this report, we showed that LDSS can be applied to plant genomes. We have successfully extracted hundreds of promoter elements as LDSS-positive octamers. All the observed behaviors of the isolated elements suggest functionality of these elements. Promoter architectures of monocot and dicot revealed in this study are well conserved, but there are moderate variations in the utilized sequences.

\section{Methods}

Preparation of promoter databases

Cap-Trapper [49] is one of the most reliable methods for identification of the 5 ' end of mRNA and thus suitable for determination of TSS. So-called full-length (fl) cDNAs of
Arabidopsis and rice were made by the Cap-Trapper method, and around ten to twenty thousand of nonredundant fl-cDNA clones for each species have been completely sequenced $[50,51]$. Therefore, we decided to use the information from the fl-cDNAs for positioning of promoters. Genome sequences of promoter regions from $-1,000$ to $-1 \mathrm{bp}$ were prepared with the aid of information of the 5' ends of fl-cDNAs of Arabidopsis [50,52] and rice [51]. The established Arabidopsis promoter database $[50,53]$ and a rice database with 11,370 promoters, prepared in this study, were utilized for our analysis.

Positions of rice fl-cDNA clones of rice [51] were mapped on to corresponding BAC clones according to description of "MappingData.txt" obtained from the KOME web site [54], and promoter regions from $-1 \mathrm{~kb}$ to $+200 \mathrm{bp}$ relative to the TSS, that are $1.2 \mathrm{kbp}$ long, were collected. BAC and fl-cDNA sequences were obtained from DDBJ. Special care was taken for 5 ' end of fl-cDNA sequences, and ones with less than 2 bp mismatch with the corresponding genomic sequences were used for the promoter mapping. Sequences of non-redundant 11,370 rice promoters have been prepared. For analyses of the TSS region, as shown in Figure 6, rice fl-cDNA sequences with no mismatch to the 5 ' end $(6,209$ promoters) were used. Establishment of the Arabidopsis promoter database is described elsewhere [50,53]. Earlier analyses with Arabidopsis hexamers have been done using the distributed database containing 15,607 promoters. This database is based on distinct TSS and allows multiple promoters belonging to a single gene. A smaller set of 12,951 promoters was re-selected from the 15,607-version so as to pick-up one promoter from one gene, and used for octamer analyses. For preparation of random genomic fragments, non-overlapping Arabidopsis BAC clones were selected by consulting a TAIR web site [55], they were successively cut into $1 \mathrm{~kb}$ pieces and serial numbers were given to the fragments. Sequences corresponding to 3,000 randomly chosen numbers based on the Mersenne Twister method [56] were used as random genomic fragments of $1 \mathrm{~kb}$ length.

The programs used in this study will be freely provided upon request for non-profit purposes. A searchable web site to obtain results in this work will be released.

\section{Generation of random distribution}

Random distribution samples were generated with respect to Total Area, that is indication of total count in a promoter database. For each Total Area, 1,000 samples were prepared, and their RPA values were subjected to statistical analysis. Average and standard deviation are functions of Total Area (Figure S1 [Additional File 2]) and affected by a smoothing window. Model RPA populations of random distribution were calculated as the following equations: 
REG detection (smoothing with a 21-bin (width of window), and Total Area < 2,000): $\log _{10}$ (average) = $0.1861 \mathrm{Ln}$ (Total Area) - 0.5329, SD =0.17 CORE detection (smoothing with a 3-bin, and Total Area < 10,000): $\log _{10}($ average $)=-0.1784 \operatorname{Ln}($ Total Area $)-0.8026, S D=$ 0.13

These models were utilized for estimation of $\mathrm{p}$ value for each octamer distribution.

\section{Sequence analysis}

Sequence analysis was achieved by a combination of home-made Perl and $\mathrm{C}^{++}$programs and also Excel software (Microsoft Japan, Tokyo). The first step of the analysis was the preparation of index files for each promoter with all the possible 4,096 hexamer and 65,536 octamer sequences. Information of the index files was then rearranged for each hexamer and octamer sequence, and the occurrence of the short sequences was summarized according to the promoter position. Summarized distribution data of each hexamer was then subjected to smoothing with a bin of 15 bp. Generally, smoothing with a wide bin lowers the peak height of a sharp peak, and with a narrow bin capturing a wide and low peak is not always possible. Considering these tendencies, a bin of 21 bp was used for identification of octamer REGs, and a bin of 3 bp was used for octamer core elements. Octamer REGs were extracted after merging the distribution data of the complementary sequence to increase the count of occurrence. As for extraction of octamer Core elements that is orientation-sensitive, merging was avoided. Positions of octamers and hexamers were counted from the first base of the sequence. For example, the position of a hexamer sequence that locates from -6 to -1 is expressed as -6 . Positions of average values for line smoothing are indicated at the centre of the region. Therefore, positions closest to TSS vary depending on the bin length as well.

Thresholds for distribution of peaks are as follows:

Hexamer: (peak height/Base Line > 3) \& (peak height/SD $>5) \&($ Peak Area/basal fluctuation) $>5$ ),

Octamer Core: (p value $<10^{-4}$ ) \& (peak height/Base Line $>5)$ \& (peak height/SD > 10) \& (Peak Area/basal fluctuation $>6) \&($ peak position $>-51)$,

Octamer REG: (p values < 10-4) \& (peak height/Base Line $>3$ ) \& (Peak Area/total area > 0.1) \& (peak height/SD > 5) $\&($ Peak Area/basal fluctuation > 6) \& (peak position <$50)$.

Fitting the distribution data with the Gaussian curve was achieved using Igor Pro (Hulinks, Tokyo). All the LDSS- positive octamers together with above parameters can be viewed at our web site ([57]).

Clustering analyses were achieved with Cluster [58] and visualized with TreeView [59]. For clustering of LDSS-positive elements based on distribution profiles, peak value of each profile was adjusted to 5.0. For REG-promoter clustering, number of each REG appeared at a region between -400 to $-40 \mathrm{bp}$ was scored for each promoter and a REG-promoter table was prepared. Among the Cluster options, the hierarchical clustering method (centroid linkage) gave the most natural results over the $k$-means and SOM methods.

Among the PLACE database [40], 48 entries with definition sequences of 8 bases or less and also with description containing "Arabidopsis" were subjected to REG survey.

\section{Abbreviations \\ LDSS - Local Distribution of Short Sequences}

TSS- transcription start site

\section{Authors' contributions}

YYY designed and performed the analyses including writing Perl programs. HI and TA prepared rice promoter database and wrote $\mathrm{C}^{++}$programs. MM, TS, MSatou, MSeki, and KS prepared Arabidopsis promoter database. JO contributed in identification of YR Rule. All authors read and approved the final manuscript.

\section{Additional material}

\section{Additional file 1}

Complete list of LDSS-positive hexamers of Arabidopsis (Table S1.pdf). Contains hexamer sequences and parameters.

Click here for file

[http://www.biomedcentral.com/content/supplementary/1471-

2164-8-67-S1.pdf]

\section{Additional file 2}

Characteristics of random distribution (FigS1.pdf). Contains graphs to show relationship between a LDSS parameter and a size of population (Total Area).

Click here for file

[http://www.biomedcentral.com/content/supplementary/14712164-8-67-S2.pdf]

\section{Additional file 3}

Arabidopsis core octamers (Table S2.pdf). Contains octamer sequences and parameters.

Click here for file

[http://www.biomedcentral.com/content/supplementary/14712164-8-67-S3.pdf] 


\author{
Additional file 4 \\ Rice core octamers (Table S3.pdf). Contains octamer sequences and \\ parameters. \\ Click here for file \\ [http://www.biomedcentral.com/content/supplementary/1471- \\ 2164-8-67-S4.pdf]

\section{Additional file 5} \\ Arabidopsis REG octamers (Table S4.pdf). Contains octamer sequences \\ and parameters. \\ Click here for file \\ [http://www.biomedcentral.com/content/supplementary/1471- \\ 2164-8-67-S5.pdf]

\section{Additional file 6} \\ Rice REG octamers (Table S5.pdf). Contains octamer sequences and \\ parameters. \\ Click here for file \\ [http://www.biomedcentral.com/content/supplementary/1471- \\ 2164-8-67-S6.pdf]

\section{Additional file 7} \\ Relationship between Arabidopsis REG and PLACE entry (Table S6.xls). \\ A table showing which octamer REG corresponds to which PLACE entry, \\ and vice versa. \\ Click here for file \\ [http://www.biomedcentral.com/content/supplementary/1471- \\ 2164-8-67-S7.xls]
}

\section{Acknowledgements}

This work was supported in part by KAKENHI (Grant-in-Aid for Scientific Research) on Priority Areas "Comparative Genomics" from the Ministry of Education, Culture, Sports, Science and Technology of Japan (to Y.Y.Y. and J.O.).

\section{References}

I. Carey M, Smale ST: Concepts and strategies: I. promoter and the general transcription machinery. In Transcriptional regulation in eukaryotes New York, Cold Spring Harbor Laboratory Press; 200 I.

2. Butler JE, Kadonaga JT: The RNA polymerase II core promoter: a key component in the regulation of gene expression. Genes Dev 2002, I 6(20):2583-2592.

3. Smale ST, Kadonaga JT: The RNA polymerase II core promoter. Annu Rev Biochem 2003, 72:449-479.

4. Antequera F, Bird A: Number of CpG islands and genes in human and mouse. Proc Natl Acad Sci USA 1993, 90(24): I I995-I I999.

5. loshikhes IP, Zhang MQ: Large-scale human promoter mapping using CpG islands. Nat Genet 2000, 26(I):6I-63.

6. Kriwacki RW, Schultz SC, Steitz TA, Caradonna JP: Sequence-specific recognition of DNA by zinc-finger peptides derived from the transcription factor Sp I. Proc Natl Acad Sci USA 1992, 89(20):9759-9763.

7. Bird A: DNA methylation patterns and epigenetic memory. Genes Dev 2002, I 6(I):6-21.

8. Blanchette M, Bataille AR, Chen X, Poitras C, Laganiere J, Lefebvre C, Deblois G, Giguere V, Ferretti V, Bergeron D, Coulombe B, Robert F: Genome-wide computational prediction of transcriptional regulatory modules reveals new insights into human gene expression. Genome Res 2006, I6(5):656-668.

9. Tatarinova T, Brover V, Troukhan M, Alexandrov N: Skew in CG content near the transcription start site in Arabidopsis thaliana. Bioinformatics 2003, I9 Suppl I:i3 I3-4.
10. Fujimori S, Washio T, Tomita M: GC-compositional strand bias around transcription start sites in plants and fungi. $B M C$ Genomics 2005, 6(I):26.

II. Bajic VB, Brent MR, Brown RH, Frankish A, Harrow J, Ohler U, Solovyev VV, Tan SL: Performance assessment of promoter predictions on ENCODE regions in the EGASP experiment. Genome Biol 2006, 7 Suppl I:S3 I-I3.

12. Sonnenburg S, Zien A, Ratsch G: ARTS: accurate recognition of transcription starts in human. Bioinformatics 2006, 22( I 4):e472-80.

13. Bajic VB, Tan SL, Suzuki Y, Sugano S: Promoter prediction analysis on the whole human genome. Nat Biotechnol 2004 , 22:1467-1473.

14. Lawrence CE, Altschul SF, Boguski MS, Liu JS, Neuwald AF, Wootton JC: Detecting subtle sequence signals: a Gibbs sampling strategy for multiple alignment. Science 1993, 262(5 I 3 I):208-2I4.

15. Roth FP, Hughes JD, Estep PW, Church GM: Finding DNA regulatory motifs within unaligned noncoding sequences clustered by whole-genome mRNA quantitation. Nat Biotechnol 1998, I 6( I 0):939-945.

16. Bailey TL, Elkan C: The value of prior knowledge in discovering motifs with MEME. Proc Int Conf Intell Syst Mol Biol 1995, 3:21-29.

17. van Helden J, Andre B, Collado-Vides J: Extracting regulatory sites from the upstream region of yeast genes by computational analysis of oligonucleotide frequencies. J Mol Biol I998, 28 I (5):827-842.

18. Hughes JD, Estep PW, Tavazoie S, Church GM: Computational identification of cis-regulatory elements associated with groups of functionally related genes in Saccharomyces cerevisiae. J Mol Biol 2000, 296(5): | 205-12 I4.

19. Ren B, Robert F, Wyrick JJ, Aparicio O, Jennings EG, Simon I, Zeitlinger J, Schreiber J, Hannett N, Kanin E, Volkert TL, Wilson CJ, Bell SP, Young RA: Genome-wide location and function of DNA binding proteins. Science 2000, 290(5500):2306-2309.

20. Lieb JD, Liu X, Botstein D, Brown PO: Promoter-specific binding of Rapl revealed by genome-wide maps of protein-DNA association. Nat Genet 200I, 28(4):327-334.

21. Manson McGuire A, Church GM: Predicting regulons and their cis-regulatory motifs by comparative genomics. Nucleic Acids Res 2000, 28(22):4523-4530.

22. Kellis M, Patterson N, Endrizzi M, Birren B, Lander ES: Sequencing and comparison of yeast species to identify genes and regulatory elements. Nature 2003, 423(6937):24I-254.

23. Harbison CT, Gordon DB, Lee TI, Rinaldi NJ, Macisaac KD, Danford TW, Hannett NM, Tagne JB, Reynolds DB, Yoo J, Jennings EG, Zeitlinger J, Pokholok DK, Kellis M, Rolfe PA, Takusagawa KT, Lander ES, Gifford DK, Fraenkel E, Young RA: Transcriptional regulatory code of a eukaryotic genome. Nature 2004, 43 I (7004):99-I 04.

24. Prakash A, Tompa M: Discovery of regulatory elements in vertebrates through comparative genomics. Nat Biotechnol 2005, 23( I 0): I249- 1256.

25. Higo K, Ugawa $Y$, Iwamoto $M$, Korenaga $T$ : Plant cis-acting regulatory DNA elements (PLACE) database: 1999. Nucleic Acids Res 1999, 27(1):297-300.

26. Davuluri RV, Sun H, Palaniswamy SK, Matthews N, Molina C, Kurtz M, Grotewold E: AGRIS: Arabidopsis gene regulatory information server, an information resource of Arabidopsis cis-regulatory elements and transcription factors. BMC Bioinformatics 2003, 4:25.

27. Steffens NO, Galuschka C, Schindler M, Bulow L, Hehl R: AthaMap: an online resource for in silico transcription factor binding sites in the Arabidopsis thaliana genome. Nucleic Acids Res 2004, 32(Database issue):D368-72.

28. Bülow L, Steffens NO, Galuschka C, Shindler M, Hehl R: AthaMap: from in silico data to real transcription factor binding sites. In Silico Biol 2006, 6:23.

29. Molina C, Grotewold E: Genome wide analysis of Arabidopsis core promoters. BMC Genomics 2005, 6(I):25.

30. Ohler U, Liao GC, Niemann H, Rubin GM: Computational analysis of core promoters in the Drosophila genome. Genome Biol 2002, 3( I 2):RESEARCH0087.

31. Elkon R, Linhart C, Sharan R, Shamir R, Shiloh Y: Genome-wide in silico identification of transcriptional regulators controlling the cell cycle in human cells. Genome Res 2003, I3(5):773-780. 
32. FitzGerald PC, Shlyakhtenko A, Mir AA, Vinson C: Clustering of DNA sequences in human promoters. Genome Res 2004, I 4(8): I $562-1574$.

33. Cooper SJ, Trinklein ND, Anton ED, Nguyen L, Myers RM: Comprehensive analysis of transcriptional promoter structure and function in $1 \%$ of the human genome. Genome Res 2006, I 6(I): I- I0.

34. Fickett JW, Hatzigeorgiou AG: Eukaryotic promoter recognition. Genome Res 1997, 7(9):86 I-878.

35. Trémousaygue D, Garnier L, Bardet C, Dabos P, Hervé C, Lescure B: Internal telomeric repeats and 'TCP domain' protein-binding sites co-operate to regulate gene expression in Arabidopsis thaliana cycling cells. Plant J 2003, 33(6):957-966.

36. Foster R, Izawa T, Chua NH: Plant bZIP proteins gather at ACGT elements. FASEB J I994, 8(2): $192-200$.

37. AtGenExpress [http://www.arabidopsis.org/info/expression/ ATGenExpress.jsp]

38. Bevan M, Walsh S: The Arabidopsis genome: a foundation for plant research. Genome Res 2005, I 5( I 2): I 632-I 642.

39. Yamaguchi-Shinozaki K, Shinozaki K: Organization of cis-acting regulatory elements in osmotic- and cold-stress-responsive promoters. Trends Plant Sci 2005, I 0(2):88-94.

40. PLACE [http://www.dna.affrc.go.jp/PLACE/]

4I. AGRIS [http://arabidopsis.med.ohio-state.edu]

42. Nakamura M, Tsunoda T, Obokata J: Photosynthesis nuclear genes generally lack TATA-boxes: a tobacco photosystem I gene responds to light through an initiator. Plant J 2002, 29(I): I- I0.

43. Carter D, Chakalova L, Osborne CS, Dai YF, Fraser P: Long-range chromatin regulatory interactions in vivo. Nat Genet 2002, 32(4):623-626.

44. Lettice LA, Horikoshi T, Heaney SJ, van Baren MJ, van der Linde HC, Breedveld GJ, Joosse M, Akarsu N, Oostra BA, Endo N, Shibata M, Suzuki M, Takahashi E, Shinka T, Nakahori Y, Ayusawa D, Nakabayashi K, Scherer SW, Heutink P, Hill RE, Noji S: Disruption of a long-range cis-acting regulator for $S h h$ causes preaxial polydactyly. Proc Natl Acad Sci USA 2002, 99(I I):7548-7553.

45. Carninci P, Sandelin A, Lenhard B, Katayama S, Shimokawa K, Ponjavic J, Semple CA, Taylor MS, Engstrom PG, Frith MC, Forrest AR, Alkema WB, Tan SL, Plessy C, Kodzius R, Ravasi T, Kasukawa T, Fukuda S, Kanamori-Katayama M, Kitazume Y, Kawaji H, Kai C, Nakamura M, Konno H, Nakano K, Mottagui-Tabar S, Arner P, Chesi A, Gustincich S, Persichetti F, Suzuki H, Grimmond SM, Wells CA, Orlando V, Wahlestedt C, Liu ET, Harbers M, Kawai J, Bajic VB, Hume DA, Hayashizaki Y: Genome-wide analysis of mammalian promoter architecture and evolution. Nat Genet 2006, 38(6):626-635

46. Yamashita R, Suzuki Y, Wakaguri H, Tsuritani K, Nakai K, Sugano S: DBTSS: DataBase of Human Transcription Start Sites, progress report 2006. Nucleic Acids Res 2006, 34(Database issue):D86-9.

47. Shahmuradov IA, Gammerman AJ, Hancock JM, Bramley PM, Solovyev VV: PlantProm: a database of plant promoter sequences. Nucleic Acids Res 2003, 3 I ( I): I I 4- I I7.

48. Lagrange T, Kapanidis AN, Tang H, Reinberg D, Ebright RH: New core promoter element in RNA polymerase II-dependent transcription: sequence-specific DNA binding by transcription factor TFIIB. Genes Dev 1998, I 2:34-44.

49. Carninci P, Kvam C, Kitamura A, Ohsumi T, Okazaki Y, Itoh M, Kamiya M, Shibata K, Sasaki N, Izawa M, Muramatsu M, Hayashizaki Y, Schneider C: High-efficiency full-length cDNA cloning by biotinylated CAP trapper. Genomics 1996, 37(3):327-336.

50. Seki M, Narusaka M, Kamiya A, Ishida J, Satou M, Sakurai T, Nakajima M, Enju A, Akiyama K, Oono Y, Muramatsu M, Hayashizaki Y, Kawa J. Carninci P, Itoh M, Ishii Y, Arakawa T, Shibata K, Shinagawa A, Shinozaki K: Functional annotation of a full-length Arabidopsis cDNA collection. Science 2002, 296(5565): |4|-|45.

5I. Kikuchi S, Satoh K, Nagata T, Kawagashira N, Doi K, Kishimoto N, Yazaki J, Ishikawa M, Yamada H, Ooka H, Hotta I, Kojima K, Namiki T, Ohneda E, Yahagi W, Suzuki K, Li C), Ohtsuki K, Shishiki T, Otomo Y, Murakami K, lida Y, Sugano S, Fujimura T, Suzuki Y, Tsunoda Y, Kurosaki T, Kodama T, Masuda H, Kobayashi M, Xie Q, Lu M, Narikawa R, Sugiyama A, Mizuno K, Yokomizo S, Niikura J, Ikeda R, Ishibiki J, Kawamata M, Yoshimura A, Miura J, Kusumegi T, Oka M, Ryu R, Ueda M, Matsubara K, Kawai J, Carninci P, Adachi J, Aizawa K, Arakawa T, Fukuda S, Hara A, Hashizume W, Hayatsu N, Imotani K, Ishii Y, Itoh M, Kagawa I, Kondo S, Konno H, Miyazaki A, Osato N,
Ota Y, Saito R, Sasaki D, Sato K, Shibata K, Shinagawa A, Shiraki T, Yoshino M, Hayashizaki Y, Yasunishi A: Collection, mapping, and annotation of over 28,000 cDNA clones from japonica rice. Science 2003, 30 I(563 I):376-379.

52. Yamada K, Lim J, Dale JM, Chen H, Shinn P, Palm CJ, Southwick AM, Wu HC, Kim C, Nguyen M, Pham P, Cheuk R, Karlin-Newmann G, Liu SX, Lam B, Sakano H, Wu T, Yu G, Miranda M, Quach HL, Tripp M, Chang CH, Lee JM, Toriumi M, Chan MM, Tang CC, Onodera CS, Deng JM, Akiyama K, Ansari Y, Arakawa T, Banh J, Banno F, Bowser L, Brooks S, Carninci P, Chao Q, Choy N, Enju A, Goldsmith AD, Gurjal M, Hansen NF, Hayashizaki Y, Johnson-Hopson C, Hsuan VW, lida K, Karnes M, Khan S, Koesema E, Ishida J, Jiang PX, Jones T, Kawa J, Kamiya A, Meyers C, Nakajima M, Narusaka M, Seki M, Sakurai T, Satou M, Tamse R, Vaysberg M, Wallender EK, Wong C, Yamamura Y, Yuan S, Shinozaki K, Davis RW, Theologis A, Ecker JR: Empirical analysis of transcriptional activity in the Arabidopsis genome. Science 2003, 302(5646):842-846.

53. Sakurai T, Satou M, Akiyama K, lida K, Seki M, Kuromori T, Ito T, Konagaya A, Toyoda T, Shinozaki K: RARGE: a large-scale database of RIKEN Arabidopsis resources ranging from transcriptome to phenome. Nucleic Acids Res 2005, 33(Database issue): D647-50.

54. KOME [http://cdna0l.dna.affrc.go.jp/cDNA/]

55. TAIR [http://www.arabidopsis.org/]

56. Matsumoto M, Nishimura T: Mersenne twister: a 623-dimensionally equidistributed uniform pseudo-random number generator. ACM Transactions on Modeling and Computer Simuation 1998, 8:3-30.

57. yamHP yamHP.html]

[http://www.gene.nagoya-u.ac.jp/ obokata-g/yyy/

Eisen MB, Spellman PT, Brown PO, Botstein D: Cluster analysis and display of genome-wide expression patterns. Proc Natl Acad Sci USA 1998, 95(25): |4863-|4868

59. EisenLab [http://rana.lbl.gov/EisenSoftware.htm

60. Kosugi S, Ohashi Y: PCF I and PCF2 specifically bind to cis elements in the rice proliferating cell nuclear antigen gene. Plant Cell 1997, 9(9): 1607-1619.

6I. Martinez-Garcia JF, Huq E, Quail PH: Direct targeting of light signals to a promoter element-bound transcription factor [see comments]. Science 2000, 288(5467):859-863.

62. Yang T, Poovaiah BW: Calcium/calmodulin-mediated signal network in plants. Trends Plant Sci 2003, 8(I 0):505-5I2.
Publish with Bio Med Central and every scientist can read your work free of charge

"BioMed Central will be the most significant development for disseminating the results of biomedical research in our lifetime. "

Sir Paul Nurse, Cancer Research UK

Your research papers will be:

- available free of charge to the entire biomedical community

- peer reviewed and published immediately upon acceptance

- cited in PubMed and archived on PubMed Central

- yours - you keep the copyright

Submit your manuscript here:

http://www.biomedcentral.com/info/publishing_adv.asp
BioMedcentral 